INTERNAL AND EXTERNAL VALIDATION OF VULNERABILTY INDICES: A CASE STUDY OF THE MULTIVARIATE NURSING HOME VULNERABILITY INDEX

\author{
A Thesis \\ by \\ MATTHEW J. WILSON
}

\author{
Submitted to the Graduate School \\ at Appalachian State University \\ in partial fulfillment of the requirements for the degree of \\ MASTER OF ARTS
}

May 2019

Department of Geography and Planning 


\title{
INTERNAL AND EXTERNAL VALIDATION OF VULNERABILTY INDICES: A CASE STUDY OF THE MULTIVARIATE NURSING HOME VULNERABILITY INDEX
}

\author{
A Thesis \\ by \\ MATTHEW J. WILSON \\ May 2018
}

APPROVED BY:

Margaret M. Sugg, Ph.D.

Chairperson, Thesis Committee

Sandi J. Lane, Ph.D.

Member, Thesis Committee

Johnathan Sugg, Ph.D.

Member, Thesis Committee

Raghuveer Mohan, Ph.D.

Member, Thesis Committee

Kathleen Schroeder, Ph.D.

Chairperson, Department of Geography and Planning

Mike McKenzie, Ph.D.

Dean, Cratis D. Williams School of Graduate Studies 
Copyright by Matthew J. Wilson 2019

All Rights Reserved 


\begin{abstract}
INTERNAL AND EXTERNAL VALIDATION OF VULNERABILTY INDICES: A CASE STUDY OF THE MULTIVARIATE NURSING HOME VULNERABILITY INDEX

Matthew J. Wilson

B.S., Appalachian State University

M.A., Appalachian State University

Chairperson: Margaret M. Sugg, Ph.D.
\end{abstract}

As the frequency of natural disasters increases, there has been an emphasis on vulnerability index creation studies. To test the validity of the most common models used in these studies, an interdisciplinary approach is used to assess the vulnerability of nursing homes throughout the Southeast (U.S). Using an inductive-hierarchical index structure; underlying community characteristics, natural hazards frequency, and nursing home facility data are combined to create the Multivariate Nursing Home Vulnerability Index (MNHVI). To internally validate these indices; a manual construction method and Monte Carlo simulations are used to create multiple unique versions of the MNHVI. Each iteration of the MNHVI considers alternative model structures for insight into regions of precision within the model and the average amount of variation for each census unit. External validation is used to determine if the indices are accurately predicting harm and mortality caused by storm events. Harm is identified at the county scale as reported by emergency management personnel, damage surveys, and local news outlets. Additionally, ICD codes from North Carolina death certificates are evaluated at the Census Tract scale with a pre/post-storm 
analysis to determine natural disasters' impact on mortality at 30/90-days pre/post-storm. Identifying accuracy and precision for vulnerability indices provides additional assurance on the appropriate identification of at-risk regions. Internal validation processes show that none of the indices were determined to be appropriately precise for either spatial resolution. The external validation processes show the hazard level analysis to be the most accurate predictor of harm/mortality for county and census tract scales. 


\section{Acknowledgments}

The procurement of this thesis would not be complete without my utmost gratitude to numerous individuals whom have assisted me along the way. While I have attempted to convey my appreciation to them along the way, I have undoubtedly been occasionally amiss in completely recognizing their influence on my development as a researcher, and most importantly, as a productive member of society. Language restricts me from properly conveying my gratitude to Dr. Maggie Sugg, my graduate advisor and thesis chairperson. Dr. Sugg's passion for her work, her drive to see her students succeed, and her willingness to sacrifice her time in order to advance the opportunities of her advisees are just some of the aspects that I respect most about her. She has challenged me academically to become the best version of myself and has assisted in my development of critical analysis and proper communication. I am hopeful that I may have the opportunity to impact and encourage someone in a manner similar to that which she has impacted and encouraged me. Without her guidance this thesis would have never been possible.

I would also be amiss if I did not properly thank my additional committee members; Dr. Sandi Lane, Dr. Johnathan Sugg, and Dr. Raghuveer Mohan. Dr. Lane provided exceptional expertise in fields of which I was previously unfamiliar. Her work ethic, attention to detail, and commitment to her students is admirable. Dr. Johnathan Sugg must have seen a small glimmer of potential in me when he kindly wrote my very first recommendation letter for graduate school. I am extremely grateful for his unique insights into geographic representation and I am excited to continue to develop on the skills which he 
helped develop within me. Dr. Mohan was a late addition to my committee but without his expertise this project would not have been nearly as strong. I have not met someone as apt in problem solving as he is and I am hopeful that through the many hours we spent together troubleshooting that I will have, at least partially, developed some of those skills.

I would like to recognize the faculty and staff of the Department of Geography and Planning at Appalachian State University. This department is home to some of the most intelligent and genuine individuals I have ever had the privilege to meet, learn from, and be in community with. I am amazed at the countless opportunities which have been afforded to me through this department. I am especially fortunate to have been under the guidance of Dr. Kara Dempsey who served as my undergraduate advisor and the department leadership of Dr. Kathleen Schroeder and Dr. Baker Perry.

Lastly, my greatest appreciation goes to my parents, Jonathan and Amy Wilson; sister, Carrie Paige Wilson; paternal grandparents, Marshall and Carolyn Wilson; and maternal grandparents, Bob and Jane Killian, for always being my biggest advocates. My family has made countless personal and financial sacrifices to support my educational endeavors and I am deeply humbled by their unconditional support. 


\section{Table of Contents}

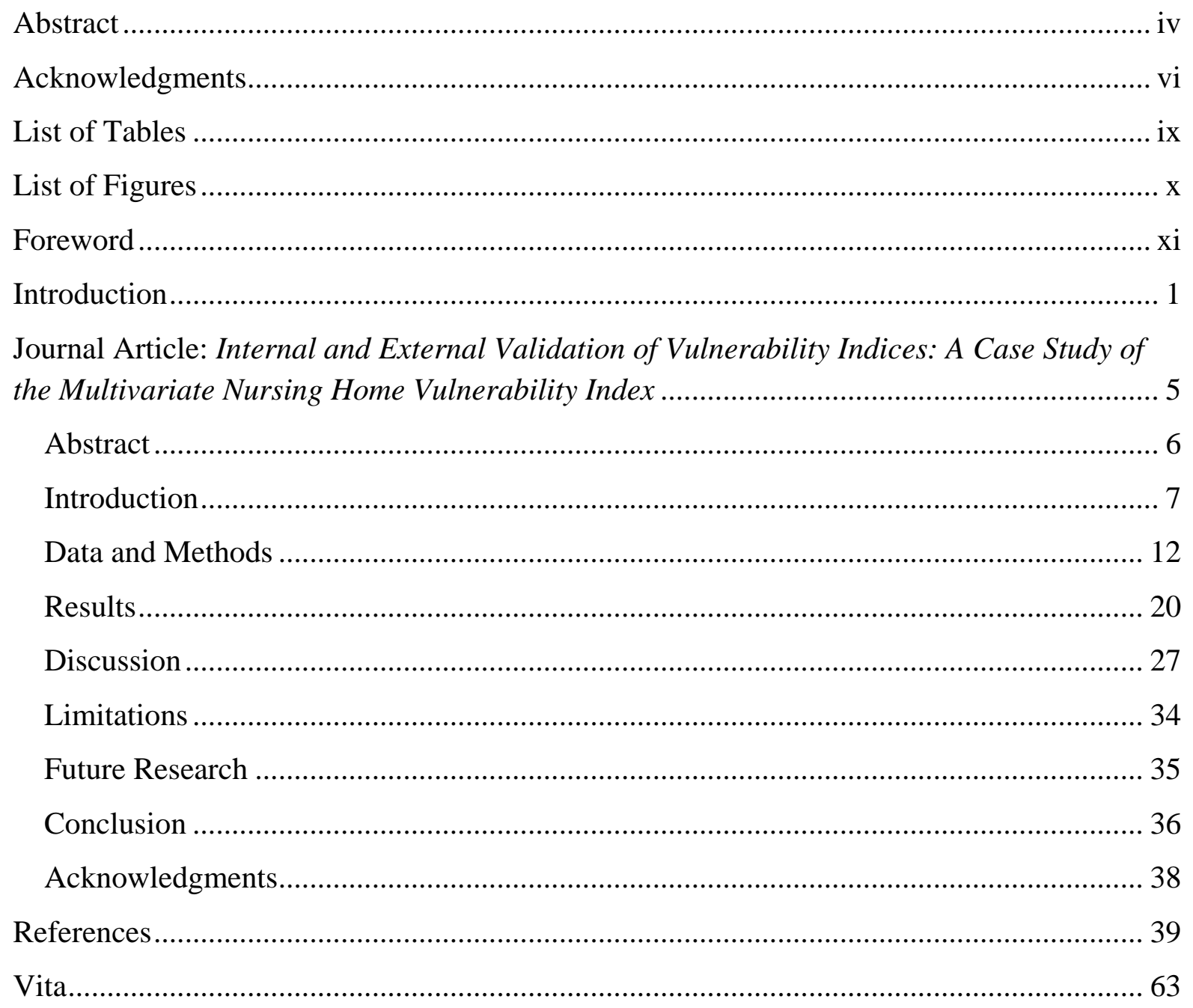




\section{List of Tables}

Table 1. Indicator sets for the three subindices (CLI, HLI, and NHLI). ................................ 48 Table 2. North Carolina mortality groups collected from ICD10 codes on North Carolina death certificates.

Table 3. Comparison of index precision for counties versus census tracts as well as a comparison of the Monte Carlo Simulation versus the manual construction method for each

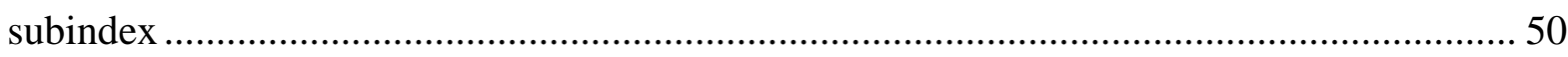

Table 4. The results of the comparison of All Harm from NOAA Storm Events compared to

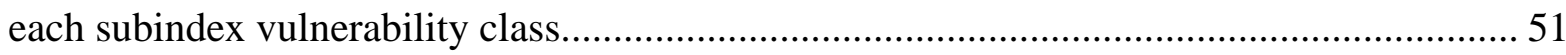

Table 5. Coefficients for HURDLE model of Total Harm for each subindex......................... 52

Table 6. The results from a Wilcoxon signed rank test with continuity correction for the 30/90-day pre- and post-storm analysis for Socioeconomic causes of death during Hurricane Irene..

Table 7. The results from a Wilcoxon signed rank test with continuity correction for the 30/90-day pre- and post-storm analysis for external causes of death and deaths in nursing homes during Hurricane Irene..

Supplementary Table 1. The results of the comparison of Deaths from NOAA Storm Events compared to each subindex vulnerability class..................................................................... 55 Supplementary Table 2. The results of the comparison of Injuries from NOAA Storm Events compared to each subindex vulnerability class.. 56 Supplementary Table 3. The results from a Wilcoxon signed rank test with continuity correction for the 30/90-day pre- and post-storm analysis for Socioeconomic causes of death during Hurricane Irene. 57 Supplementary Table 4. The results from a Wilcoxon signed rank test with continuity correction for the 90-day pre- and post-storm analysis for external causes of death and deaths in nursing homes during Hurricane Irene. 58 


\section{List of Figures}

Fig. 1. Inductive Hierarchial Model of Index Construction.............................................. 59

Fig. 2. Trivariate Map of Vulnerabilty in the Southeastern United States. .......................... 60

Fig. 3. Census Tracts Exposed to Hurricane Irene............................................................. 61

Fig. 4. Results from the Manual Contruction Method and the Monte Carlo Simulation. ...... 62 


\section{Foreword}

The main body of this thesis is formatted to the guidelines for manuscript submission to Applied Geography, an official journal published quarterly by Elsevier which publishes studies that utilize geographic approaches (human, physical, and GIScience) to resolve human problems that have a spatial dimension. 


\section{Introduction}

In the first three months of 2018, the United States experienced 3 billion-dollar disasters and 2017 saw fifteen different billion-dollar disasters (NOAA, 2017; NOAA, 2018). Since 1980 there was been an observable increase in the frequency and number of annual billion-dollar weather disasters occurring within the United States (NCEI, 2018). The increase in these hazardous events has prompted a shift in preparation strategies from emergency management personnel and response programs (Cutter, Boruff, \& Shirley, 2003; FEMA, 2018). This emphasis on disaster preparation method reanalysis has resulted in a required collaborative effort between healthcare facilities and their community partners using an “all-hazards” approach (DHHS, 2016). Subsequently, natural hazards and social vulnerability fields of research have responded to these disastrous events and new public policies by analyzing social vulnerability to extreme weather events (Chakraborty, Tobin, \& Montz, 2005; Cutter \& Emrich, 2006; Cutter \& Finch, 2008; DHHS, 2016; Flanagan, Gregory, Hallisey, Heitgerd, \& Lewis, 2011; Montz \& Tobin, 2011).

The body of existing literature on natural hazards is a combination of research from various social and natural sciences, public policy and safety, health and human services, and information technology (Montz \& Tobin, 2011; Tobin \& Montz, 2004). The culmination of these various fields into one collective field of natural hazard and social vulnerability research allow for more than theoretical models to be created. Instead, models have been adapted and implemented in such a way that emphasizes the importance of understanding and studying the intersection between geophysical conditions, community and social systems, and vulnerable demographics (e.g., nursing homes). A unifying and unavoidable 
aspect of this area of research is the need to identify the influence of spatial location on vulnerability distribution across a region.

Natural hazards are a spatial phenomenon. The spatial distribution of certain hazards will result in regions of vulnerability that are different for each category of hazard (e.g., tropical cyclone, flooding, freezing, winter storm). Geographic research on this topic has helped investigators cross the human-environment divide as well as incorporate researchers from outside disciplines. The ability to study vulnerability with an interdisciplinary approach provides an opportunity to investigate physical processes, human populations and demographics, socio-ecological vulnerability, statistical modeling processes, and geovisualization strategies (Adger, Hughes, Folke, Carpenter, \& Rockstrom, 2005; Andrew, Mitniski, \& Rockwood, 2008; Cutter \& Emrich, 2006; Cutter, Gall, \& Emrich, 2008; Dosa, Hyer, Thomas, Swaminathan, Feng, Brown, \& Mor, 2012; Emrich \& Cutter, 2011; Evans, 2010; Feizizadeh \& Blaschke, 2014; Haines, Kovats, Campbell-Lendrum, \& Corvalan, 2006; MacEachren \& Kraak, 2001; Montz \& Tobin, 2011; Perdikaris, Gharabaghi, \& McBean, 2011; Tate, 2012). Previous research has focused on the identification of a social systems' vulnerability to specific natural hazards such as hurricanes (Cutter \& Emrich, 2006), flooding (Adger et al., 2005; Perdikaris, Gharabaghi, \& McBean, 2011), and wildfire (Wigtil, Hammer, Kline, Mockrin, Stweard, Roper, \& Radeloff, 2016). Other studies, however, have taken a multi-hazard approach to identifying vulnerability of social systems to multiple climatic and socially-sensitive hazards (Berrouet, Machado, \& Villegas-Palacio, 2018; Cutter, Boruff, \& Shirley, 2003; Emrich \& Cutter, 2011; Füssel, 2007; McLaughlin \& Dietz, 2008; Nguyen, Bonetti, Rogers, \& Woodroffe, 2015). 
An increasingly useful and implemented method for quantitatively and visually identifying regions of vulnerability is through vulnerability indices. Hames, Stoler, Emrich, Tweary, \& Pandya (2017) identified the need to spatially identify socially and medically vulnerable older adult populations through a vulnerability index creation study which was a derivative of Cutter’s Social Vulnerability Index (SoVI) (2003) and Morath’s MedVI (2010). Cutter's SoVI has since become the most spatial assessment of vulnerability at the national and sub-national level. The quantitative assessment of vulnerability (which is typically understood as a subjective experience and therefore better studied qualitatively) makes the SoVI a relatively simple method to visually and numerically convey complex underlying processes (Tate, 2012). The SoVI uses the socio-economic variables within a region to assess their potential hazard vulnerability, preparedness, response, and recovery at a static point in time (Emrich \& Cutter, 2011). The SoVI model has been reproduced in many of the aforementioned articles and its design produces an easily distributable and palatable product to the general public.

The need to validate indices stems from a problem inherent in multi-criteria decision analysis (MCDA). MCDA is primarily concerned with identifying how to combine data from multi-source, multi-temporal, multi-scale, and multi-spatial sources into a singular index (Chen, Yu, \& Khan, 2010; Green, Devillers, Luther, \& Eddy, 2011). The culmination of multiple data sources into a singular index requires the creator to make subjective decisions about the appropriate stages of index development (e.g., model structure, analysis scale, variable transformation, variable normalization, weighting of factors, data aggregation) which will add uncertainty into the results (Crosetto \& Tarantola, 2001; Tate, 2012). Each stage of model construction should be repeated thousands of times using a Monte Carlo 
simulation to create a baseline index which can be compared to the GIS-MCDA output to evaluate confidence in the index (Tate, 2013). A recent study examining vulnerability to landslides demonstrated how a GIS-MCDA uncertainty analysis increased the level of confidence in the GIS-MCDA process by identifying confidence intervals for the model output using AHP-Monte Carlo methodology (Feizizadeh \& Kienberger, 2017).

Implementing GIS-MCDA for vulnerability analysis helps researchers create easily distributable and palatable outputs that can be incorporated into public policy and emergency management procedures. When vulnerability index results are combined with external validation (e.g., age-adjusted rates of mortality), uncertainty analysis, and sensitivity analysis, a final vulnerability index can be created that can help facilitate appropriate responses from emergency management personnel and nursing home administrators. 


\title{
INTERNAL AND EXTERNAL VALIDATION OF VULNERABILTY INDICES: A CASE STUDY OF THE MULTIVARIATE NURSING HOME VULNERABILITY INDEX
}

\author{
Matthew J. Wilson ${ }^{1}$ Margaret M. Sugg ${ }^{1}$, Sandi J. Lane ${ }^{2}$, Johnathan Sugg ${ }^{1}$, \\ Raghuveer Mohan ${ }^{3}$
}

${ }^{1}$ Department of Geography and Planning, Appalachian State University, Boone, NC, USA

${ }^{2}$ Department of Health Care Management, Appalachian State University, Boone, NC, USA

${ }^{3}$ Department of Computer Science, Appalachian State University, Boone, NC, USA 


\section{Abstract}

As the frequency of natural disasters increases, there has been an emphasis on vulnerability index creation studies. To test the validity of the most common models used in these studies, an interdisciplinary approach is used to assess the vulnerability of nursing homes throughout the Southeast (U.S). Using an inductive-hierarchical index structure; underlying community characteristics, natural hazards frequency, and nursing home facility data are combined to create the Multivariate Nursing Home Vulnerability Index (MNHVI). To internally validate these indices; a manual construction method and Monte Carlo simulations are used to create multiple unique versions of the MNHVI. Each iteration of the MNHVI considers alternative model structures for insight into regions of precision within the model and the average amount of variation for each census unit. External validation is used to determine if the indices are accurately predicting harm and mortality caused by storm events. Harm is identified at the county scale as reported by emergency management personnel, damage surveys, and local news outlets. Additionally, ICD codes from North Carolina death certificates are evaluated at the Census Tract scale with a pre/post-storm analysis to determine natural disasters’ impact on mortality at 30/90-days pre/post-storm. Identifying accuracy and precision for vulnerability indices provides additional assurance on the appropriate identification of at-risk regions. Internal validation processes show that none of the indices were determined to be appropriately precise for either spatial resolution. The external validation processes show the hazard level analysis to be the most accurate predictor of harm/mortality for county and census tract scales. 


\section{Introduction}

Since the 1980s, the United States has experienced a measurable increase in the frequency and severity of billion-dollar disasters (NCEI, 2018). In 2018 there were 11 weather-related disasters, which resulted in at least one billion dollars in losses; 2017 experienced 15 such events (NOAA, 2017; NOAA, 2018). The increasing frequency of these events has prompted research in hazards and vulnerability fields that seeks to identify relative vulnerability to these disasters. This field of study has resulted in new mitigation strategies for emergency management personnel as well as an emphasis on collaborative efforts between public officials, communities, and healthcare facilities (Cutter, Boruff, \& Shirley, 2003; DHHS, 2016; FEMA, 2018). A seemingly inevitable and encouraging result from this outpouring of vulnerability research is that natural hazards and social vulnerability fields of research have responded through research, public discourse, and legislation in an attempt to diminish societal vulnerability to extreme weather events (Chakraborty et al., 2005; Cutter \& Emrich, 2006; Cutter \& Finch, 2008; DHHS, 2016; Flanagan et al., 2011; Montz \& Tobin, 2011).

This area of study is inherently interdisciplinary which allows for unique perspectives into the needs and weaknesses of potentially marginalized populations. Previous studies have identified older adults as having a higher likelihood to experience harm from natural disasters than their younger neighbors (Brunkard, Namulanda, \& Ratard, 2008; Cutter \& Finch, 2008; Malik, Lee, Doran, Grudzen, Worthing, Portelli, Goldfrank, \& Smith, 2018). The source of this disproportionate vulnerability can be explained by a variety of reasons, most of which fall into the broad categories of existing physical and cognitive conditions - which are often present in older adults residing in skilled nursing facilities. These physical and cognitive 
conditions can make recovering from stressful situations difficult, causing prolonged harm on this vulnerable demographic long after the storm ends. Dosa et al. (2012) calculated that at 30-days post-Katrina there were an additional 277 deaths and 872 hospitalizations; at 90days, 579 deaths and 544 additional hospitalizations for nursing home residents aged 65+ which could be attributed to the storm. Similarly, $50 \%$ of the post-Katrina deaths were adults aged 75+ (Rothman \& Brown, 2007), and 12\% of deaths from Katrina and Rita were from nursing home residents (Brunkard, Namulanda, \& Ratard, 2008).

The body of existing literature on natural hazards is a combination of research from various social and natural sciences, public policy and safety, health and human services, and information technology (Montz \& Tobin, 2011; Tobin \& Montz, 2004). The ability to study vulnerability with an interdisciplinary approach provides an opportunity to investigate physical processes, human populations and demographics, socio-ecological vulnerability, statistical modeling processes, and geovisualization strategies (Adger et al., 2005; Andrew et al., 2008; Cutter \& Emrich, 2006; Cutter \& Finch, 2008; Dosa et al., 2012; Emrich \& Cutter, 2011; Evans, 2010; Feizizadeh \& Blaschke, 2014; Haines et al., 2006; MacEachren \& Kraak, 2001; Montz \& Tobin, 2011; Peduzzi, 2009; Perdikaris, Gharabaghi, \& McBean, 2011; Pielke, Rubiera, Landsea, Fernandez, \& Klein, 2003; Tate, 2012). Previous research has focused on the identification of a social systems' vulnerability to specific natural hazards such as hurricanes (Cutter \& Emrich, 2006; Pielke et al., 2003), flooding (Adger et al., 2005; Perdikaris, Gharabaghi, \& McBean, 2011), and wildfire (Wigtil et al., 2016). Other studies, however, have taken a multi-hazard approach to identifying vulnerability of social systems to multiple climatic and socially-sensitive hazards (Berrouet, Machado, \& Villegas-Palacio, 
2018; Cutter, Boruff, \& Shirley, 2003; Emrich \& Cutter, 2011; Füssel, 2007; McLaughlin \& Dietz, 2008; Nguyen et al., 2015; Peduzzi, 2009).

The culmination of these various fields into one collective field of natural hazard and social vulnerability research allows for more than theoretical models to be created. Instead, models have been adapted and implemented in such a way that emphasizes the importance of understanding and studying the intersection between geophysical conditions, community and social systems, and vulnerable demographics (e.g., nursing home residents). A unifying and unavoidable aspect of this area of research is the need to identify the influence of spatial location on vulnerability distribution across a region. An increasingly useful and implemented method for quantitatively and visually identifying regions of vulnerability is through vulnerability indices.

Specifically relating to older adults, which is a point of emphasis of this paper, there was an article written (Hames et al., 2017) which identified the need to spatially identify socially and medically vulnerable older adult populations through a vulnerability index creation study which was a derivative of Cutter’s Social Vulnerability Index (SoVI) (2003) and Morath’s MedVI (2010). The quantitative assessment of vulnerability (which is typically understood as a subjective experience and therefore better studied qualitatively) makes the SoVI a relatively simple method to visually and numerically convey complex underlying processes (Tate, 2012). The SoVI uses the socio-economic variables within a region to assess their potential hazard vulnerability, preparedness, response, and recovery at a static point in time (Emrich \& Cutter, 2011). The SoVI model has been reproduced in many of the aforementioned articles and its design produces an easily distributable and palatable product to the general public. 
While index creation studies have become increasingly used, and the outputs they produce can be helpful for emergency management agencies and nursing home administrators, there has been an identified need to attribute confidence intervals and uncertainty within each index (Tate, 2012). Validation of indices can be done internally or externally. External validation of vulnerability indices has been done using mortality data (Gall, 2007; Knowlton, Rotkin-Ellman, King, Margolis, Smith, Solomon, \& English, 2008) and economic losses (Schmidtlein, Schafer, Berry, \& Cutter, 2010; Cutter, Gall, \& Emrich, 2008; Gall, Borden, \& Cutter, 2009). For an analysis of nursing home vulnerability, mortality is likely the most plausible form of external validation. Internal validation is more difficult. However, despite this difficulty, it is pertinent to verify that each model is performing precisely before vulnerability index results can be confidently implemented into public policy and emergency management decisions (Tate, 2013).

The need to validate indices stems from a problem inherent in multi-criteria decision analysis (MCDA). MCDA is primarily concerned with identifying how to combine data from multi-source, multi-temporal, multi-scale, and multi-spatial sources into a singular index (Chen et al., 2010; Green et al., 2011). The culmination of multiple data sources into a singular index requires the creator to make subjective decisions about the appropriate stages of index development (e.g., model structure, analysis scale, variable transformation, variable normalization, weighting of factors, data aggregation) which will add uncertainty into the results (Crosetto \& Tarantola, 2001; Tate, 2012). Each stage of model construction should be repeated thousands of times using a Monte Carlo simulation to create a baseline index which can be compared to the GIS-MCDA output to evaluate confidence in the index (Tate, 2013). A recent study examining vulnerability to landslides demonstrated how a GIS-MCDA 
uncertainty analysis increased the level of confidence in the GIS-MCDA process by identifying confidence intervals for the model output using AHP-Monte Carlo methodology (Feizizadeh \& Kienberger, 2017).

Previously, the authors have created a multivariate index which considers variables of three categories (Community/Social, Hazards, and Nursing Facilities), we have created an inductive-hierarchial index which is titled the Multivariate Nursing Home Vulnerability Index (MNHVI). The model structure follows an inductive-hierarchical design since it combines a Principal Component Analysis (PCA) with the Analytical Hierarchy Process (AHP) to identify rates of relative vulnerability across the Southeastern United States (SEUS) to hazards related to the three categories listed above (Figure 1). The purpose of this study is to implement both the external and internal modes of validation of the MNHVI which previous peer-reviewed literature has suggested. By testing these statistical validation techniques, the authors hope to add to the discourse on the validity of vulnerability index creation studies being used in emergency management plans and legislation as well as provide an easily replicated framework for internally and externally validating future indices. 


\section{Data and Methods}

The study area chosen for this study is composed of ten states within the Southeastern United States: Alabama, Florida, Georgia, Kentucky, Mississippi, North Carolina, South Carolina, Tennessee, Virginia, and West Virginia. These states were selected due to their proximity to the Gulf and Atlantic coasts, where tropical cyclone and other extreme weather events are common (e.g., tornadoes, flash floods). Flooding and events associated with flooding (e.g., tropical cyclones) have been previously identified as a major concern for nursing home residents (Time, 2017). The emphasis on flood-related disasters makes the SEUS the optimal region for this analysis.

Data were collected at the nursing home facility level $(n=2,824)$ and census tract level $(n=16,284)$ to assess fine-scale patterns of vulnerability across the study area. Map outputs were aggregated to the county level ( $\mathrm{n}=924)$ to aid visual interpretation when appropriate.

Data were compiled from various sources and multiple vulnerability indices were created and then combined to create a composite vulnerability index (Table 1). The three indices create a triangulated approach to identifying multivariate vulnerability for nursing home facilities. One sub-index was created to examine socioeconomic and community characteristics for each census tract which is titled the Community Level Index (CLI) (Figure 1.1). The second sub-index examines the frequency of natural hazard occurrences for each tract which is titled the Hazard Level Index (HLI) (Figure 1.3). The third sub-index examines the vulnerability of nursing homes using facility-level data which is titled the Nursing Home Level Index (NHLI) (Figure 1.2). The composite index created from the CLI, HLI, and NHLI is titled the Multivariate Nursing Home Vulnerability Index (MNHVI) (Figure 1.4). Drivers of each CU are calculated and visualized in Figure 2. 
The inductive structure is chosen for the HLI and the CLI due to a lack of consensus on which variables are most influential on vulnerability and multicollinearity within the variables, as well as its frequency of use within previous studies (Cutter, Boruff, \& Shirley, 2003; Hames et al., 2017; Rygel, O’Sullivan, \& Yarnal, 2006; Schmidtlein, Deutsch, Piegorsch, \& Cutter, 2008). The HLI was created with 15 natural hazard variables (Table 1.1) selected from the Homeland Infrastructure Foundation Level Database (HIFLD), the National Oceanic and Atmospheric Administration (NOAA), and the Federal Emergency Management Agency (FEMA) and 23 socioeconomic variables (Table 1.2) are selected for the CLI from the U.S. Census 2015 American Community Survey (ACS) 5-year estimates.

The hierarchical structure is chosen for the NHLI, and not for the CLI and the HLI, due to an existing literature of organizational theory, which identifies the variables most influential on resident vulnerability (Dosa et al., 2012; Laditka, Laditka, Xirasagar, Cornman, Davis, \& Richter, 2008; Morris, Fries, Mehr, Hawes, Phillips, Mor, \& Lipsitz, 1994; Morris, Fries, \& Morris, 1999). This body of literature, in conjunction with the ability to incorporate nuanced opinions from current and former experts within fields relating to the care of older adults, make the hierarchical approach, with AHP methodology most appropriate for the NHLI. Variables for this sub-index were chosen from a freely available database titled the Nursing Home Compare Minimum Data Set (MDS) from the Centers for Medicare \& Medicaid Services (CMS).

These data for the NHLI provide insight into the functional, emotional, cognitive, and disease status for all long-term residents within CMS Nursing Homes across the nation, as well as public use staffing files and ownership information (Table 1.3). The AHP methods used for this index poll expert opinions $(n=5)$ on variable importance using ranks 1-9 (least 
critical to most critical). Experts were chosen according to a convenience sample of persons with current or previous occupational or research experience in long-term care facilities. Averaged expert ranks are used in the AHP to reduce complexity of a decision according to a pairwise comparisons matrix which evaluates each variable compared to one another.

The values with the comparison matrix are normalized in order to calculate the eigenvalues. The largest eigenvalue in the matrix is isolated and placed into a formula titled the Consistency Index (CI). The CI value is compared with the Random Consistency Index (RI) value given by Saaty (1980) to determine if the weights calculated by summing the rows are appropriate. The process of comparing the $\mathrm{CI}$ with the RI is done by calculating the Consistency Ratio (CR). If the $\mathrm{CR}$ value is acceptable $(\mathrm{CR}<0.1)$ then the variable weights calculated above are considered appropriate and can be used in the hierarchical structural approach (Alonoso \& Lamata, 2006; Saaty, 1980; Teknomo, 2017).

Each variable associated with nursing home facilities, collected from the Centers for Medicare and Medicaid Services Nursing Home Compare database, was standardized using z-score standardization producing a mean of 0 and a standard deviation of 1 . Upon determining that the AHP devised weights are appropriate for this model construction, the corresponding weights are applied to the variables. The subsequent NHLI vulnerability scores for each nursing home facility are identified as the summation of the products between each standardized variable and its corresponding AHP derived weight.

Each nursing home facility is ascribed an NHLI vulnerability score. The nursing facilities are geocoded and layered on top of both the census tract and county level U.S. Census Tiger/Line shapefiles. To test the hypothesis that nursing home residents and facilities are potentially more vulnerable due to their geographic location and not only from 
residents’ pre-existing physical and cognitive conditions; the three sub-indices must be combined. Without an existing body of literature to support any unequal weighting method, an equal weights hierarchical structure is used. CLI, HLI, and NHLI scores are standardized using $\mathrm{z}$-score standardization so that the mean $=0$ and the standard deviation $=1$. Each index has previously been joined to the corresponding geographic unit and therefore all that needs to be done is to sum the three standardized index values. The resultant value is the MNHVI score.

\subsection{Internal Validation}

After the creation of the three sub-indices (i.e., CLI, HLI, and NHLI) and aggregating them to multiple scales, using an equal weights hierarchical model, we validated the subindices internally by identifying how model stage alteration impacted vulnerability classification for each independent Census Unit (CU).

The internal validation is used to identify the consistency of index rankings for each CU regardless of which model structure decision is made (e.g., precision, Tate 2012). Model stage choices which were evaluated are: Analysis Scale (i.e., County or Census Tract), Normalization (i.e., Z-Score or Min-Max Linear Scaling), and Weighting (i.e., Equal Weights or Expert Ranks). Similar to previous research, we used a Monte Carlo simulation to evaluate index precision under varying model stages (Feizizadeh \& Blaschke, 2014; Tate, 2013).

The hypotheses which the internal validation is working under are: 1) Manual construction of each sub-index and the composite index will show similar variability in results as the Monte Carlo simulation, regardless of the number of simulations which are run ( $\mathrm{n}=4,100$, or 1000); and 2) Identification of variability from internal validation will 
highlight that index results are least precise in the "highest” vulnerability classes (Tate, 2012). Manual construction, for internal validation, is the process of calculating index scores for each CU without the use of simulations or estimations. Therefore, an index score was manually calculated for each alternative stage choice (i.e., normalization, weighting) so that every possible model stage combination was considered once.

The absolute value of the average index score from every possible model structure is taken and ranked. As index ranks increase, vulnerability classification also increases (e.g., a rank of $1=$ Very Low Vulnerability and $924=$ Very High Vulnerability). These rankings are done for both analysis scales. The points on the curve which lay below the x-axis are representative of CUs which are below average (low and very low vulnerability). Likewise, points on the curve which lay above the x-axis are representative of CUs which are above average (high and very high vulnerability).

The $y$-axis is the measure of variation which is determined by the Coefficient of Variation (CV) for each CU (Brown, 1998). The smaller the value on the y-axis, the more precise the CU is across all possible model structures. Precision implies repeatability and consistency of vulnerability rankings regardless of model construction processes. In other words, the internal validation asks the question: if changes are made in the index creation process, does the vulnerability ranking stay relatively the same? If vulnerability rankings are found to stay consistent across various model construction processes, then that $\mathrm{CU}$ is determined to be precise. Accuracy is determined through external validation and will be outlined in the next section.

Similar to Tate (2013) we identified that CV values less than 12 indicated high precision while CV values less than 40 indicated moderate precision. Any CV values above 
40 were classified as low precision. Due to non-normality, a Spearman’s Correlation Coefficient (SCC) is calculated for the CV value and the median vulnerability score calculated from every possible model structure for each CU. All internal validation was conducted in R and R studio (R Core Team, 2018).

\subsection{External Validation: NOAA Storm Events}

Data: The NOAA Storm Events database allows for a broad view of harm, at the county scale, attributable to natural disasters through emergency management personnel, damage surveys, local news outlets, and skywarn spotters, and serves as an effective source for validating the indices (i.e., CLI, HLI, NHLI, MNHVI), it is also desired to get more detailed data for validation purposes (NOAA Storm Events, 2019). Direct and indirect deaths were combined to determine the total number of deaths, likewise, direct and indirect injuries were combined to determine the total number of injuries. Totals for deaths and injuries were combined to calculate the total harm caused either by a storm or over a selected period of time at the county level. These data were accessed through the noaastormevents package, in conjunction with the hurricaneexposuredata package in R (Anderson \& Chen, 2017; Anderson, Schumacher, Crosson, Al-Hamdan, Yan, Ferreri, Chen, Quiring, \& Guikema, 2017).

Statistical Analysis: To determine the external validity of each sub-index as well as the composite index (i.e., MNHVI), multiple stages of analysis are necessary. Initially, a count of occurrences of harm are created at the county scale. Those instances of harm (i.e.,

Direct/Indirect Deaths, Direct/Indirect Injuries, Total Deaths, Total Injuries, Total Harm) are then categorized by the vulnerability grouping, which was previously ascribed to each CU. Percentages of harm are calculated for each sub-index and the MNHVI (Table 3). Lastly, to 
determine which index was the best predictor for all-harm (all death and injuries) a hurdle model with a negative binomial distributed was constructed to account for excess zeros and over-dispersion. Rootograms and traditional model-comparison criteria such as, AIC confirmed model selection compared to other count based models (i.e., Poisson, ZeroInflated Poisson, Zero-Inflated Negative Binomial). Hurdle models were constructed using the pscl package (Zeileis, Kleiber, \& Jackman, 2008).

\subsection{External Validation: Death Certificates}

Data: The second data source for the external validation portion of the study was from the North Carolina Department of Health and Human Services, State Center for Health Statistics. Data were collected for each instance of mortality across a 14 year period (20002013) for specified ICD and ACMECOD codes (Table 2) and geocoded in R according to the individuals place of residence and then aggregated to the Census Tract (Kahle \& Wickham, 2013). Data were then grouped into various categories according to the causes of death and analyses conducted on each of the groups (Table 2.1-2.4).

As previous research has suggested, post-disaster rates of mortality can be observed with a lag period (Dosa, 2012). To account for this lag period, a comparison of total of mortality for each Census Tract across North Carolina, pre- and post-disaster, for each subindex vulnerability class for two lag periods (30-days post disaster and 90-days post disaster). Average mortality per Census Tract and total mortality across the state are compared across the two lag periods. A Wilcoxon signed rank test with continuity correction is used to determine if there is a significant difference between the occurrences of mortality, pre- and post-storm, for both lag periods. 
Two spatial scales were examined for external validation across the same time period. The storm selected was Hurricane Irene (2011), which made landfall in northeast NC, on the coast of the Outer Banks and resulted in estimates of $\$ 15.8$ billion dollars in damage (Freedman, 2012). This storm was selected for its coastal flooding and hurricane level winds. The initial spatial scale was for the entire state of North Carolina at the Census Tract level. The second spatial scale was as subset of North Carolina tracts which were directly exposed to the storm (Figure 3). Results were consistent among both spatial scales.

Occurrences of mortality are subset according to each category of mortality type (i.e., socioeconomic causes of death, deaths within nursing homes, external causes) for the first time period (Hurricane Irene), are isolated for 90 and 30 days pre- and post-storm. The average deaths per CU as well as total deaths across North Carolina are calculated at 90 and 30 days pre- and post-storm by using the formula where $\mathrm{X}$ represents the number of deaths prior to the storm, $\mathrm{Y}$ represents the number of deaths post storm: $\mathrm{X}-\mathrm{Y}=\mathrm{Z}$. Therefore, any number displayed as a negative means that there were more deaths in the period after the storm, and any number displayed as a positive means that there were more deaths in the period before the storm. 


\section{Results}

\subsection{Internal Validation}

\subsubsection{Community Level Index (CLI)}

The CLI, at the County level, had 20 CUs, which had CV values $<|40|$ for both the manual construction method and the Monte Carlo simulation (2.16\% of the study area) (Table 1). All of the CUs that were found to be moderately precise were classified as Very High vulnerability.

The CLI, at the Census Tract level, had 378 CUs which had CV values $<|40|$ for both the manual construction method and the Monte Carlo simulation (2.39\% of the study area) compared to 20 counties at the county level (2.16\% of the study area) (Table 1$)$. This indicates that CLI is only slightly more precise at the Census Tract level than at the County level. Of the CUs which were found to be moderately precise, 377 were classified as Very High vulnerability and 1 was classified as Very Low vulnerability.

Graphic outputs for the Monte Carlo simulation and the manual construction method were made for each of the four indices. Figure 6 displays the output for the CLI at both CU scales, using both methods. Points below the x-axis are for CUs with negative CV values, indicating that the mean vulnerability score for that CU was negative, placing it in the Very Low, Low or Average vulnerability class, depending on the quartiles for the specific index. The closer to the x-axis that a point lies, the more precise that index is considered to be. Each sub index displays graphic outputs comparable to Figure 6, therefore, only the Monte Carlo for the CLI will be shown, but readers should be aware that this trend is constant across all indices.

The SCC for the County level is 0.43 for both the manual construction and the Monte Carlo and the SCC for the Census Tract level is 0.45 for both the manual construction and the 
Monte Carlo (p-value < 0.01). The slight positive SCC values show that as vulnerability ranks increase, the precision also increases.

\subsubsection{Hazard Level Index (HLI)}

The HLI, at the County level, had 25 CUs (2.71\% of the study area) which had CV values $<|40|$ for both the manual construction method and the Monte Carlo simulation (Table 1). All of the CUs which were found to be moderately precise were classified as Very High vulnerability. Only one HLI CU at the County level had a CV value $<\mid 12$ for both the manual construction method and the Monte Carlo simulation. This CU is Miami-Dade County, FL which was also had the highest HLI vulnerability across the SEUS at the County level as well.

At the Census Tract level, the HLI had 559 CUs which had CV values $<|40|$ for the manual construction method (3.55\% of study area) and 574 CUs for the Monte Carlo simulation (3.65\% of study area) (Table 1). Similar to the County level HLI, all of the CUs which were found to be moderately precise were classified as Very High vulnerability. Of all HLI CUs, 13 had a CV value $<|12|$ for both the manual construction method and the Monte Carlo simulation, which equates to $0.1 \%$ of the study area, similar to the HLI at the County level. These 13 CUs are predominantly coastal; 12 of which are located across Florida, and 1 is located in Hyde County, NC.

The SCC for the County level HLI is 0.378 for both the manual construction and the Monte Carlo and the SCC for the Census Tract level is 0.414 for the manual construction and is 0.441 for the Monte Carlo (p-values < 0.01). Similar to the CLI, the positive SCC values for the HLI suggest that as vulnerability ranks increase, the precision also increases. 


\subsubsection{Nursing Home Level Index}

The NHLI, at the County level, had 65 CUs (7.03\% of the study area), which had CV values $<|40|$ for the manual construction method and 66 CUs (7.14\%) for the Monte Carlo simulation (Table 1). All of the CUs which were found to be moderately precise were classified as Very High vulnerability.

At the Census Tract level, the NHLI had 1412 CUs (8.97\% of the study area) which had CV values $<|40|$ for the manual construction method and 1370 CUs (8.70\%) for the Monte Carlo simulation (Table 1). Similar to the CLI and the HLI, all of the CUs which were found to be moderately precise were classified as Very High vulnerability.

A Pearson's correlation was used for NHLI since the distribution of these data were found to be normally distributed. The Pearson's correlation coefficient for the County level NHLI for the manual construction and the Monte Carlo is -0.215 and the Pearson's correlation coefficient for the Census Tract level manual construction is -0.19 and is -0.18 for the Monte Carlo, all values are found to be significant $(\mathrm{p}<0.01)$.

\subsubsection{Multivariate Nursing Home Vulnerability Index (MNHVI)}

The MNHVI, at the County level, had 27 CUs (2.92\% of the study area) which had CV values $<|40|$ for the manual construction method and 26 CUs (2.81\%) for the Monte Carlo simulation (Table 1). All of the CUs which were found to be moderately precise classified as Very High vulnerability.

The MHNVI, at the Census Tract level, had 591 CUs (3.75\% of the study area) which had CV values $<|40|$ for the manual construction method and 549 CUs (3.49\%) for the Monte Carlo simulation (Table 1). All CUs which were found to be moderately precise were classified as Very High vulnerability. 
The SCC for the manual construction at the County level is 0.254 and the SCC for the County level Monte Carlo is 0.272 (p-value $<0.01$ ). The SCC for the manual construction at the Census Tract level is 0.321 and the SCC for the Monte Carlo is 0.356 (p-value $<0.01$ ). The slight positive SCC values show that as vulnerability ranks increase, the precision also increases, however, the trend is so low that it suggests no real relationship exists.

\subsection{External Validation: NOAA Storm Events}

The external validation process is used to identify if (and where) each index is accurate. To examine external validity of each index seven dependent variables were considered: Direct Death, Indirect Death, Total Death, Direct Injury, Indirect Injury, Total Injury, All Harm (Table 4). The HLI is the most accurate with $46 \%$ of all harm occurring in CUs classified as Very High vulnerability and 66\% of harm occurring in CUs with above average vulnerability. The MNHVI is the second most accurate index with $30 \%$ of harm occurring in CUs classified as High vulnerability and 51\% occurring in CUs with above average vulnerability. The CLI experienced $30 \%$ of all harm in CUs classified as Average vulnerability and only 33\% of harm occurring in CUs with above average vulnerability. The NHLI experienced 38\% harm in CUs identified as Low vulnerability and only 26\% of harm occurring in CUs considered to have above average vulnerability.

\subsubsection{NOAA Storm Events Death}

The HLI was the best predictor of death with over $45 \%$ of all deaths found to be caused by a storm event occurring in CUs classified as Very High vulnerability according to the HLI (Supplementary Table 1). The NHLI was the worst predictor of deaths associated with vulnerability across the SEUS. Approximately 32\% of deaths in this category occurred in CUs classified as Low vulnerability according to the NHLI. For the remaining two indices, 
the largest percentage of death which occurred across the region occurred in CUs classified as High in the CLI (26\%) and in CUs classified as Very High for the MNHVI (34\%). The proportion of direct and indirect deaths for each vulnerability class can be seen in Supplementary Table 1.

\subsubsection{NOAA Storm Events Injuries}

Likewise, the HLI was the best predictor of injury found to be caused by a storm event (45\% in CUs classified as Very High vulnerability) (Supplementary Table 2). The NHLI was the worst predictor of injuries across the SEUS. Just under $40 \%$ of all injuries associated with a storm event occurred in CUs classified as Low vulnerability for the NHLI. The MNHVI observed 32\% of injuries associated with a storm in CUs classified as High vulnerability and the CLI observed 32\% of injuries in CUs classified as Average vulnerability. The proportion of direct and indirect injuries for each vulnerability class can be seen in Supplementary Table 2.

\subsubsection{NOAA Storm Events Regression Results}

Each sub-index was assessed as a predictor for all-harm counts (i.e., all deaths and injuries) using a hurdle model with a negative binomial model distribution. To account for a large number of zeroes, the hurdle model reports two types of coefficients, one that predicts the presence or absence of a zero and another that accounts for greater than 1 death or injury. In both cases, the HLI predicted the greatest increase in self-harm with incidence rate ratios of 2.38 (CI: 1.79-3.16) and 2.02 (CI:1.50-2.73), respectively. Surprisingly, the NHLI and CLI were protective factors in the zero-hurdle model, and thus did not contribute to self harm death or injuries with incidence rate ratios of less than 1.0 (NHLI CI: 0.37-0.96, CLI CI: 0.86-0.97). NHLI was also insignificant when predicting more than one self-harm event (CI: 
0.00-5.09), highlighting the subindices inability to accurately predict death/injury NOAA events accurately.

\subsection{External Validation: NC Death Certificates}

Considering socioeconomic causes of death for Hurricane Irene, we see a significant difference between occurrences of death 90 days prior to the storm and 90 days post storm for each vulnerability class in each index across North Carolina (p-value $<0.01$ ) (Table 6). In general, deaths categorized as socioeconomically caused and occurring 30 days prior/post Hurricane Irene were not determined to be significant different ( $\mathrm{p}$-value $>0.10)$. However, there was an increase in the occurrences of mortality 30 days after Hurricane Irene for CUs identified to have Very High vulnerability for the HLI (p-value < 0.10).

Deaths categorized as occurring within nursing homes were found to have a significant increase in deaths 90 days after Hurricane Irene (Table 7). No vulnerability class for any of the four indices were found to have a significant difference in occurrences of death within nursing homes 30 days pre- and post-storm.

Differences in deaths categorized as having external causes, 30 days before and after Hurricane Irene, were not found have any significant differences. At the 90 day scale, however, each vulnerability class in each of the four indices were found to be significant to either the 90th, 95th, or 99th percentile with the exception of Average and Very High vulnerability in the NHLI (Table 7).

Considering the subset of CUs exposed to Hurricane Irene which experienced socioeconomic causes of death, we see a significant difference between occurrences of death 90 days prior to the storm and 90 days post storm for the majority of vulnerability classes in each index across North Carolina (p-value $<0.01$ and p-value $<0.05$ ) with the exception of the 
NHLI High vulnerability class (p-value>0.1) (Supplementary Table 3). In general, deaths categorized as socioeconomically caused and occurring 30 days prior/post Hurricane Irene were not determined to be significant different (i.e., p-value $>0.10$ ). However, there was an increase in the occurrences of mortality 30 days after Hurricane Irene for CUs exposed that were identified to have Very High vulnerability for the HLI (p-value<0.05), Low vulnerability for the NHLI (p-value<0.05), and Very Low vulnerability for the MNHVI (pvalue $<0.01$ ) (Supplementary Table 3).

Of deaths categorized as occurring within nursing homes, in CUs which were exposed to Hurricane Irene, some were found to have a significant increase in deaths 90 days after Hurricane Irene (Supplementary Table 4). The HLI and MNHVI were found to be more significant as vulnerability increased, whereas the NHLI decreased in significance as vulnerability increased. The CLI was significant for all vulnerability classes. No vulnerability class for any of the four indices were found to have a significant difference in occurrences of death within nursing homes 30 days pre- and post-storm.

Differences in external causes of deaths (30 days before and after Hurricane Irene) for CUs exposed to Hurricane Irene were not found have any significant differences. At the 90day scale, however, seven vulnerability classes in the four indices were found to be significant ( $\mathrm{p}$-value $<0.01$, $\mathrm{p}$-value $<0.05$, or $\mathrm{p}$-value $<0.10$ ). These significant increases in death are found in the CLI: Low, HLI: Very High, NHLI: Very Low, and Low, MNHVI: Low, Average, and Very High vulnerability classes (Supplementary Table 4). 


\section{Discussion}

Vulnerability indices with varying topics of emphasis (e.g., wildfire, coastal, flood) continue to be created and implemented at various scales worldwide (Balica, Douben, \& Wright, 2009; McLaughlin, McKenna, \& Cooper, 2002; Wigtil et al., 2016). The ability to visually and quantitatively identify sources and clusters of vulnerability across a geographic region make these indices a desirable asset for local governments and emergency management personnel. Previous studies have taken a multi-hazards approach of vulnerability identification (Berrouet, Machado, \& Villegas-Palacio, 2018; Cutter, Boruff, \& Shirley, 2003; Emrich \& Cutter, 2011; Füssel, 2007; McLaughlin \& Dietz, 2008; Nguyen et al., 2015) while others have taken a hazard-specific approach (Adger et al., 2005; Cutter \& Emrich, 2006; Perdikaris, Gharabaghi, \& McBean, 2011; Wigtil et al., 2016). Coinciding with this breadth of literature, there are various accepted index creation methodologies which has resulted in a lack of validation to ensure results are robust, accurate, and precise (Gall, 2007; Tate, 2012). As indices continue to be incorporated in discussions about public policy decisions, it is vital to identify areas of uncertainty and imprecision within vulnerability indices to ensure appropriate decisions are made (Tate, 2013).

In this study, precision is calculated through internal validation of an index. Internal validation tests the repeatability of index values when incremental changes occur at different stages in the model structure. It is important to verify that the model is repeatable, and therefore precise, before the vulnerability index can be confidently implemented into public policy and emergency management discussions (Tate, 2013). In this study, we examined the precision for the three sub-indices (CLI, HLI, NHLI) and the composite index (MNHVI) to understand the CUs with vulnerability scores that can be repeated across various model 
structure alterations. None of the indices, as a whole, were found to be precise. However, we did observe slight trends of increased precision as vulnerability increases.

In general, the NHLI was determined to have the highest percentage of moderately precise CUs of the indices. These results correspond to the lack of variability within the nursing home dataset where many CUs have either no nursing homes or only one nursing home, making the NHLI more consistent due to the small sample size. The HLI was the only index which contained $\mathrm{CU}(\mathrm{s})$ within the highly precise grouping (CV values $<|12|$ ), showing that, at the extremes, the HLI is more precise than any of the other indices. Likewise, Figure 6 displays a decreases in CV values as average ranks increase, suggesting that the vulnerability extremes are comparatively more precise compared to other lower vulnerability levels. The CUs found to be highly precise in the HLI were the CUs determined to be the most vulnerable for this index, further confirming this trend. The MNHVI was found to have higher percentages of moderately precise CUs than both the HLI and CLI, which is likely do to the incorporation of the more consistent NHLI variables within the MNHVI.

Our precision results contrast with Tate (2013) who found for SoVI, a strong significant decrease in precision as index rank increases $(\mathrm{R}=-0.71)$. Instead, we found for similar indices, like the CLI, which uses the same variables as SoVI a SCC of 0.43 or an increase in precision as index rank increases. Several reasons may explain our contradictory findings, including the use non-parametric statistical techniques (e.g., Spearman’s Correlation Coefficient), a smaller subset of model alterations under examination, or a larger study region (e.g., 924 counties). Moreover, the spread of CV values in Tate (2013) is much smaller than the spread of CV values used in our study. Therefore, CV values considered to be at the extremes of Tate's study (i.e., CV's 100-160) are relatively frequent for our 
analysis. Lastly, the imprecision experienced in specific indices, like the NHLI, may also be attributed to the use of the AHP process, which has been criticized due to its subjectivity in comparison judgments made by experts (Feizizadeh \& Kienberger, 2017).

Precision was consistently higher when data were aggregated to the Census Tract level, likely due to the modifiable areal units problem (MAUP), which typically results in significant results at more aggregate levels. While the differences in percentages of moderate precision between the county level and the Census Tract level were not always significant, the higher rates of consistency for the Census Tract level, even if only a few tenths of a percentage, show that estimating vulnerability is potentially better suited for smaller geographies.

Previous studies have recommended using a Monte Carlo simulation to evaluate index precision under varying model stages and typically include more model stage iterations than this study (Feizizadeh \& Blaschke, 2014; Tate, 2013). Since there were fewer alternatives for this analysis, we evaluated the necessity of incorporating a Monte Carlo simulation, with several numbers of repetitions $(n=4,100$, and 1000$)$ versus manually comparing each alteration through the manual construction method. Overall, there is no significant difference between the rates of precision between the manual construction method and the Monte Carlo Simulation. However, depending on the number of stages which a researcher wants to consider, the manual construction method may be more desirable and would require little to no knowledge of advanced statistical processes. In contrast, in scenarios where the number of index stages increases, the manual construction method may become too labor intensive and would, therefore, be more suited for the Monte Carlo 
simulation method (Feizizadeh \& Kienberger, 2017). Regardless of which methodology is chosen, our findings suggest results will remain consistent between the two options.

In our study, accuracy was calculated through external validation of each index, using categorical mortality data through death certificate ICD-10 codes as well as instances of harm from severe storms according to emergency management personnel, damage surveys, and local news outlets (NOAA Storm Events, 2019). Previous studies have attempted external validation of indices using mortality data (Gall, 2007) and economic losses (Cutter, Gall, \& Emrich, 2008; Gall, Borden, \& Cutter, 2009; Schmidtlein et al., 2010). The incorporation of external validation allows for insight into good indices and bad indices (Gall, 2007). A good index is one which correlates highly with the external source of validation (i.e., occurrences of mortality/harm) and its indicators whereas a bad index is one which does not correlate to the external data (Booysen, 2002; Gall, 2007).

Overall, all harm (i.e., Direct Death, Indirect Death, Total Death, Direct Injury, Indirect Injury, Total Injury) validated the HLI index best, with 66\% occurred in CUs classified as above average vulnerability, $46 \%$ of which occurred in the Very High vulnerability class. The NHLI was the least accurate of the sub-indices with only $27 \%$ of harm being accurately predicted. This is, however, unsurprising since the data used in the NHLI are not specific to natural hazards and are, instead, intended to identify the comparative vulnerabilities of nursing homes due to facility-level data. External validation results were confirmed with hurdle regression analysis, which found the HLI was the only predictor of NOAA all-harm events that increased the risk of having a death/injury significantly (Incidence Rate Ratios > 1.0). In contrast, the CLI, and NHLI were protective factors (Incidence Rate Ratios < 1.0) that decreased risk of self-harm. 
When broken down into subcategories (i.e., types of Death and types of Injury) we observe the same general pattern. Again, the HLI is most accurate of the four indices for predicting death and injury at the county level for the SEUS. Since the MNHVI is mostly driven by the HLI, it is expected and observed that the MNHVI would be the second best predictor. The fact that the HLI and the MNHVI are the most accurate of the indices supports the hypothesis that geographic location, and the location of frequent natural hazards, has a large impact on a regional vulnerability.

To examine external validation at both the census tract and county level, death certificate data were compiled for North Carolina and categorized according to cause of death. Socioeconomic causes of death were considered the most comprehensive grouping and held the largest sample size (containing deaths within nursing homes and external causes of death), which may account for some of its significance. The comprehensive grouping method, which considers all types of mortality, has been considered a promising external validation proxy (Gall, 2007), nonetheless, dividing the deaths into sub-groups was appropriate due to the nature of the sub-indices. Despite the perceived necessity of mortality groupings, both of the spatial scales for the pre- and post-Hurricane Irene analysis display comparable findings across all groups. For deaths categorized as socioeconomic (considered our most comprehensive grouping), the 90-day pre/post-storm analysis shows a significant increase in deaths 90 days after the storm for all North Carolina CUs as well as the majority of North Carolina CUs, which were directly exposed to the storm.

Our accuracy results confirm the findings of Dosa et al. (2012) where there was an increase in overall hospitalizations and mortality rates for nursing home residents post-storm. Our results differ from, and add to, these previous findings by analyzing the occurrences of 
mortality per vulnerability class. The increases in death post-storm identified in this study help to identify which indices are more accurate, however, there is an understood need for more accurate death certificate data, especially for deaths from natural hazards which often go unreported or incorrectly reported (Gall, 2007). While the large significant differences in pre/post-storm deaths in above average vulnerability tracts provide evidence that the indices are accurate, the equally large significant differences in below average tracts counteract this hypothesis. Despite the potential inaccuracies in death certificate data, the findings from this study suggest that when a region experiences a hurricane, there will be an increase in the occurrences of mortality across all vulnerability classes. These findings, in conjunction with the impossibility of preventing storms from occurring, show that it may be in researchers best interest emphasize hazard vulnerability models instead of social vulnerability models, for future adaptation strategy, and vulnerability assessment studies (Pielke et al., 2003).

Deaths in nursing homes were predicted best by the MNHVI and the HLI; a finding which is supported by the NOAA Storm Events portion of the external validation. The MNHVI and HLI showed a significant difference in deaths 90 days after Irene for CUs which were exposed to the storm and classified as above average vulnerability. These findings are congruent to the findings of Dosa et al. (2012), which observed an increase in overall deaths and hospitalizations experienced by nursing home residents both 30- and 90-days post-storm. Whereas the NHLI was the worst predictor of nursing home deaths with below average vulnerability CUs finding a larger significant difference in the number of deaths than CUs with above average vulnerability. This is made evident when examining the number of poststorm deaths within nursing homes; 828 deaths in CUs with below average NHLI vulnerability and only 91 deaths in CUs with above average NHLI vulnerability. The lack of 
accuracy in the NHLI suggests that facility-level data may not be the most appropriate scale of analysis, especially when data are aggregated to a larger CU. It is also not expected that determining vulnerability among nursing home residents would lend itself to being a good predictor of harm from natural disasters. It is not logical to expect that a CU that has low NHLI vulnerability is less likely to experience a natural disaster.

Similar to deaths in nursing homes, the HLI is the most accurate predictor of deaths from external causes and the NHLI is the least accurate predictor of these deaths. These findings, along with the results from the initial, County level external validation, using NOAA Storm Events, seem to suggest that it may be most appropriate to encourage vulnerability index creation studies which emphasize the prediction and detailed analysis of nuances of natural disasters and their likelihood at smaller scales, instead of only emphasizing social systems (i.e., Peduzzi et al., 2009). Studies of this nature are likely to experience higher rates of accuracy for predicting occurrences of mortality and may contain less confounding variables when compared to socioeconomic/demographically driven datasets. 


\section{Limitations}

This study contains several accepted limitations. First, the selection of data for index creation, while supported by relevant literature (i.e., Cutter et al., 2003; Tate, 2012; Schmidtlein et al., 2008), was subjective and subject to scrutiny. Likewise, the selection of model stages to consider for the internal validation portion of the study could be expanded to include other uncertainties, such as the choice of indicator sets used for the CLI. The amount of uncertainty from the American Community Survey (ACS) is up to 75\% more than the decennial census (Spielman, Folch, \& Nagle, 2014); the use of ACS data undoubtedly limited the amount of potential precision within our model. Additions to (or omissions of) model stages will certainly have an impact on the observed precision of each index. Death certificate data were only available to researchers for the state of North Carolina, which reduced the scale at which the external validation at the census tract scale. The external validation would be benefited by incorporating additional proxy sources (i.e., hospitalization data, insurance claims, property damage, etc.), which could provide a more detailed picture of harm caused by natural hazards. 


\section{Future Research}

Our study is one of the first to provide a comprehensive validation of multiple vulnerability indices across a large geographic region. In order to enhance the results found in this study, future research should incorporate additional natural hazard events into the HLI in order to create an all-encompassing disaster risk index. The identification of the HLI to be the most accurate of the indices is a key finding that emphasizes further research into the geographic prediction of harm specifics to natural hazards. The creation of a disaster risk index at a sub-national scale will enable researchers to better predict where instances of harm will occur from severe storm events. Additionally, harm from other natural hazards (i.e., tornados, wildfire, tropical cyclones, severe flooding events) should be assessed for external validity as well. Future research should also consider additional model stages (i.e., decennial census data as another indicator set) to further understand the impact of methodology on the precision of vulnerability indices. Lastly, a key methodological finding of this study demonstrates that future indices do not necessarily require the use of a Monte Carlo Simulation to determine index precision when the Manual Construction method is plausible (i.e., sample sizes are small enough to reasonably replicate for each alteration in model structure). This finding gives researchers the ability to validate their indices even if they do not have extensive experience in advanced computational processes and statistical coding. 


\section{Conclusion}

Ultimately, the lack of overall precision among our indices illustrates that index creation and uncertainty calculation needs to be confidently implemented into public policy and discourse. Indicator sets used in the creation of these indices should also be more thoroughly examined as uncertainty is embedded within these datasets, and researchers are often given few alternatives for data collection (Feizizadeh \& Kienberger, 2017). The visual and quantitative products, which vulnerability index creation studies produce, are extremely helpful tools, but only to the extent that the results are precise and repeatable. More work is needed to determine the most appropriate model stages for precisely identifying vulnerability and how to ensure, at least, moderately precise results. Investigation of how these indices would have predicted real-world mortality is another vital step in index validation that also incorporates the accuracy or ability to successfully externally validate an index.

This study of internal and external validation adds to the discourse on the validity of vulnerability indices for public policy implementation. This analysis also provides an easily replicated methodology, which may be implemented in future studies to determine the efficacy of previously made indices, as well as indices yet to come. While vulnerability indices certainly make effective visual and quantitative products, it is suggested that researchers, local officials, and public policy makers alike take pause to internally and externally validate their findings before putting these results into policy actions. The HLI, being the most accurate of the indices, provides evidence that it may be more appropriate to emphasize the creation of disaster risk indices as opposed social vulnerability indices when attempting to predict and mitigate loss and harm from natural disasters. While the HLI may have predicted harm most accurately, there was little precision across all indices. The overall imprecision of these models suggests that officials should seek further evidence of 
vulnerability (social or physical) before altering disaster mitigation strategies. Ultimately, the intent of this study is to benefit past and future index creation studies with the ultimate goal of preventing loss of property and lives, which can only be done with accurate and precise models. 


\section{Acknowledgments}

The authors thank Lauren Andersen who assisted in data collection and analysis

during the early stages of the project. This project was also made possible by the College of Arts and Sciences Student and Faculty Excellence (SAFE) Fund. 


\section{References}

Adger, W. N., Hughes, T. P., Folke, C., Carpenter, S. R., \& Rockström, J. (2005). Socialecological resilience to coastal disasters. Science, 309(5737), 1036-1039.

Alonso, J. A., \& Lamata, M. T. (2006). Consistency in the analytic hierarchy process: a new approach. International journal of uncertainty, fuzziness and knowledge-based systems, 14(04), 445-459.

Anderson, B., Schumacher, A., Crosson, W., Al-Hamdan, M., Yan, M., Ferreri, J., Chen, Z., Quiring, S., Guikema, S. (2017). hurricaneexposuredata: Data Characterizing Exposure to Hurricanes in United States Counties. R package version 0.0.2. https://github.com/geanders/hurricaneexposuredata.

Anderson, B. \& Chen, Z. (2017). noaastormevents: Explore NOAA Storm Events Database. R package version 0.1.0. https://CRAN.Rproject.org/package=noaastormevents

Andrew, M. K., Mitnitski, A. B., \& Rockwood, K. (2008). Social vulnerability, frailty and mortality in elderly people. PloS one, 3(5), e2232.

Balica, S. F., Douben, N., \& Wright, N. G. (2009). Flood vulnerability indices at varying spatial scales. Water science and Technology, 60(10), 2571-2580.

Berrouet, L. M., Machado, J., \& Villegas-Palacio, C. (2018). Vulnerability of socio—Ecological systems: A conceptual Framework. Ecological Indicators, 84, 632-647.

Booysen, F. (2002). An overview and evaluation of composite indices of development. Social indicators research, 59(2), 115-151.

Brown, C. E. (1998). Coefficient of variation. In Applied multivariate statistics in geohydrology and related sciences(pp. 155-157). Springer, Berlin, Heidelberg.

Brown, L., Rothman, M., \& Norris, F. (2007). Issues in mental health care for older adults 
after disasters. Generations, 31(4), 21-26.

Brunkard, J., Namulanda, G., \& Ratard, R. (2008). Hurricane katrina deaths, louisiana, 2005. Disaster medicine and public health preparedness, 2(4), 215-223.

CDC. (2002). Instruction Manual [PDF file]. Retrieved from, https://www.cdc.gov/nchs/data/dvs/im9_2002.pdf.pdf

Chakraborty, J., Tobin, G. A., \& Montz, B. E. (2005). Population evacuation: assessing spatial variability in geophysical risk and social vulnerability to natural hazards. Natural Hazards Review, 6(1), 23-33.

Chen, Y., Yu, J., \& Khan, S. (2010). Spatial sensitivity analysis of multi-criteria weights in GIS-based land suitability evaluation. Environmental modelling \& software, 25(12), 1582-1591.

CMS (2019, February 25). Nursing Home Compare database. Retrieved from https://data.medicare.gov/data/nursing-home-compare

Crosetto, M., \& Tarantola, S. (2001). Uncertainty and sensitivity analysis: tools for GISbased model implementation. International Journal of Geographical Information Science, 15(5), 415-437.

Cutter, S. L., Boruff, B. J., \& Shirley, W. L. (2003). Social vulnerability to environmental hazards. Social science quarterly, 84(2), 242-261.

Cutter, S. L., \& Emrich, C. T. (2006). Moral hazard, social catastrophe: The changing face of vulnerability along the hurricane coasts. The Annals of the American Academy of Political and Social Science, 604(1), 102-112.

Cutter, S. L., \& Finch, C. (2008). Temporal and spatial changes in social vulnerability to 
natural hazards. Proceedings of the National Academy of Sciences, 105(7), 23012306.

Cutter, S. L., Gall, M., \& Emrich, C. T. (2008). Toward a comprehensive loss inventory of weather and climate hazards. Climate extremes and society, 279-295.

DHHS (2016). Medicare and Medicaid Programs; Emergency Preparedness

Requirements for Medicare and Medicaid Participating Providers and Suppliers; Final Rule. Federal Register 81(180), 63859-64044 [PDF file]. Retrieved from https://www.gpo.gov/fdsys/pkg/FR-2016-09-16/pdf/2016-21404.pdf

Dosa, D., Hyer, K., Thomas, K., Swaminathan, S., Feng, Z., Brown, L., \& Mor, V. (2012). To evacuate or shelter in place: implications of universal hurricane evacuation policies on nursing home residents. Journal of the American Medical Directors Association, 13(2), 190-e1.

Emrich, C. T., \& Cutter, S. L. (2011). Social vulnerability to climate-sensitive hazards in the southern United States. Weather, Climate, and Society, 3(3), 193-208.

Evans, J. (2010). Mapping the vulnerability of older persons to disasters. International journal of older people nursing, 5(1), 63-70.

FEMA. (2018, August 17). 2018-2022 strategic plan. Helping people. Together. Retrieved from https://www.fema.gov/strategic-plan

Feizizadeh, B., Jankowski, P., \& Blaschke, T. (2014). A GIS based spatially-explicit sensitivity and uncertainty analysis approach for multi-criteria decision analysis. Computers \& geosciences, 64, 81-95.

Feizizadeh, B., \& Kienberger, S. (2017). Spatially explicit sensitivity and uncertainty 
analysis for multicriteria-based vulnerability assessment. Journal of Environmental Planning and Management, 60(11), 2013-2035.

Flanagan, B. E., Gregory, E. W., Hallisey, E. J., Heitgerd, J. L., \& Lewis, B. (2011). A social vulnerability index for disaster management. Journal of homeland security and emergency management, 8(1).

Freedman, A. (2012, May 10). Hurricane Irene ranked most costly category 1 storm. Retrieved from https://www.climatecentral.org/news/hurricane-irene-ranked-mostcostly-category-1-storm

Füssel, H. M. (2007). Vulnerability: A generally applicable conceptual framework for climate change research. Global environmental change, 17(2), 155-167.

Galea, S., Ahern, J., \& Karpati, A. (2005). A model of underlying socioeconomic vulnerability in human populations: evidence from variability in population health and implications for public health. Social Science \& Medicine, 60(11), 2417-2430.

Gall, M. (2007). Indices of social vulnerability to natural hazards: a comparative evaluation. University of South Carolina. Ann Arbor, 231.

Gall, M., Borden, K. A., \& Cutter, S. L. (2009). When do losses count? Six fallacies of natural hazards loss data. Bulletin of the American Meteorological Society, 90(6), 799-810.

Greene, R., Devillers, R., Luther, J. E., \& Eddy, B. G. (2011). GIS-based multiple-criteria decision analysis. Geography Compass, 5(6), 412-432.

Haines, A., Kovats, R. S., Campbell-Lendrum, D., \& Corvalán, C. (2006). Climate change and human health: impacts, vulnerability and public health. Public health, 120(7), 585-596. 
Hames, E., Stoler, J., Emrich, C. T., Tewary, S., \& Pandya, N. (2016). A GIS approach to identifying socially and medically vulnerable older adult populations in South Florida. The Gerontologist, 57(6), 1133-1141.

HIFLD. (2018, December 1). Homeland Infrastructure Foundation-Level Data. Retrieved from, https://hifld-geoplatform.opendata.arcgis.com/

Kahle, D., \& Wickham, H. (2013). ggmap: spatial visualization with ggplot2. $R$ Journal, 5(1).

Knowlton, K., Rotkin-Ellman, M., King, G., Margolis, H. G., Smith, D., Solomon, G. \& English, P. (2008). The 2006 California heat wave: impacts on hospitalizations and emergency department visits. Environmental health perspectives, 117(1), 61-67.

Laditka, S. B., Laditka, J. N., Xirasagar, S., Cornman, C. B., Davis, C. B., \& Richter, J. V. (2008). Providing shelter to nursing home evacuees in disasters: lessons from Hurricane Katrina. American journal of public health, 98(7), 1288-1293.

MacEachren, A. M., \& Kraak, M. J. (2001). Research challenges in geovisualization. Cartography and geographic information science, 28(1), 3-12.

Maercker, A., Brewin, C. R., Bryant, R. A., Cloitre, M., van Ommeren, M., Jones, L. M., \& Somasundaram, D. J. (2013). Diagnosis and classification of disorders specifically associated with stress: proposals for ICD-11. World Psychiatry, 12(3), 198-206.

Malik, S., Lee, D. C., Doran, K. M., Grudzen, C. R., Worthing, J., Portelli, I., \& Smith, S.W. (2018). Vulnerability of older adults in disasters: emergency department utilization by geriatric patients after Hurricane Sandy. Disaster medicine and public health preparedness, 12(2), 184-193.

McLaughlin, S., McKenna, J., \& Cooper, J. A. G. (2002). Socio-economic data in coastal 
vulnerability indices: constraints and opportunities. Journal of Coastal Research, 36(sp1), 487-497.

McLaughlin, P., \& Dietz, T. (2008). Structure, agency and environment: Toward an integrated perspective on vulnerability. Global Environmental Change, 18(1), 99-111.

Montz, B. E., \& Tobin, G. A. (2011). Natural hazards: An evolving tradition in applied geography. Applied Geography, 31(1), 1-4.

Morath, D. P. (2010). Social vulnerability and public health: Developing a metric for medical emergency management in Florida. A thesis presented for the degree of Master of Science at the University of South Carolina.

Morris, J. N., Fries, B. E., Mehr, D. R., Hawes, C., Phillips, C., Mor, V., \& Lipsitz, L. A. (1994). MDS cognitive performance scale@. Journal of gerontology, 49(4), M174M182.

Morris, J. N., Fries, B. E., \& Morris, S. A. (1999). Scaling ADLs within the MDS. The Journals of Gerontology: Series A, 54(11), M546-M553.

NFHL. (2017, November 11). National Flood Hazard Layer. Retrieved from, https://catalog.data.gov/dataset/national-flood-hazard-layer-nfhl/resource/89b88927fc8e-4557-a97f-3f3729aad36d

Nguyen, T. T., Bonetti, J., Rogers, K., \& Woodroffe, C. D. (2016). Indicator-based assessment of climate-change impacts on coasts: A review of concepts, methodological approaches and vulnerability indices. Ocean \& Coastal Management, 123, 18-43.

NHC. (2017, November 11). Storm Surge Maximum of the Maximum (MOM). Retrieved from https://www.nhc.noaa.gov/surge/momOverview.php 
NOAA. (2017, June 28). Billion-dollar weather and climate disasters: Table of events. NOAA National Centers for Environmental Information. Retrieved from https://www.ncdc.noaa.gov/billions/events/US/2017.

NOAA. (2018, September 15). U.S. hit with 3 billion-dollar disasters in first 3 months of 2018. Retrieved from https://www.noaa.gov/news/us-hit-with-3-billion-dollar-disasters-in-first-3-monthsof-2018

NOAA National Centers for Environmental Information (NCEI). (2018, September 15). U.S. Billion-Dollar Weather and Climate Disasters. Retrieved from https://www.ncdc.noaa.gov/billions/

NOAA Storm Events. (2019, February 1). Database Details. Retrieved from https://www.ncdc.noaa.gov/stormevents/

Peduzzi, P., Dao, H., Herold, C., \& Mouton, F. (2009). Assessing global exposure and vulnerability towards natural hazards: the Disaster Risk Index. Natural Hazards and Earth System Sciences, 9(4), 1149-1159.

Perdikaris, J., Gharabaghi, B., \& McBean, E. (2011). A methodology for undertaking vulnerability assessments of flood susceptible communities. International journal of safety and security engineering, 1(2), 126-146.

Pielke Jr, R. A., Rubiera, J., Landsea, C., Fernández, M. L., \& Klein, R. (2003). Hurricane vulnerability in Latin America and the Caribbean: Normalized damage and loss potentials. Natural Hazards Review, 4(3), 101-114.

R Core Team (2018). R: A language and environment for statistical computing. $\mathrm{R}$ 
Foundation for Statistical Computing, Vienna, Austria. URL https://www.Rproject.org/.

Rothman, M., \& Brown, L. (2007). The vulnerable geriatric casualty: medical needs of frail older adults during disasters. Generations, 31(4), 16-20.

Rygel, L., O’sullivan, D., \& Yarnal, B. (2006). A method for constructing a social vulnerability index: an application to hurricane storm surges in a developed country. Mitigation and adaptation strategies for global change, 11(3), 741-764.

Saaty, T. L. (1980). Analytic heirarchy process. Wiley statsRef: Statistics reference online.

Schmidtlein, M. C., Deutsch, R. C., Piegorsch, W. W., \& Cutter, S. L. (2008). A sensitivity analysis of the social vulnerability index. Risk Analysis: An International Journal, 28(4), 1099-1114.

Schmidtlein, M. C., Shafer, J. M., Berry, M., \& Cutter, S. L. (2011). Modeled earthquake losses and social vulnerability in Charleston, South Carolina. Applied Geography, 31(1), 269-281.

Spielman, S. E., Folch, D., \& Nagle, N. (2014). Patterns and causes of uncertainty in the American Community Survey. Applied Geography, 46, 147-157.

Tate, E. (2012). Social vulnerability indices: a comparative assessment using uncertainty and sensitivity analysis. Natural Hazards, 63(2), 325-347.

Tate, E. (2013). Uncertainty analysis for a social vulnerability index. Annals of the association of American geographers, 103(3), 526-543.

Teknomo, K. (2017, August 17). Analytic hierarchy process (AHP). Retrieved from http://people.revoledu.com/kardi/tutorial/AHP/

Thacker, M. T., Lee, R., Sabogal, R. I., \& Henderson, A. (2008). Overview of deaths 
associated with natural events, United States, 1979-2004. Disasters, 32(2), 303-315.

Time. (2017, December 3). 'Need help asap.' The story behind the photo of nursing home residents trapped in hurricane flood water. U.S. - Texas. Retrieved from http://time.com/4917743/la-vita-bella-nursing-home-dickinson-texas-photo/

Tobin, G. A., \& Montz, B. E. (2004). Natural hazards and technology: vulnerability, risk, and community response in hazardous environments. In Geography and Technology (pp. 547-570). Springer, Dordrecht.

Wigtil, G., Hammer, R. B., Kline, J. D., Mockrin, M. H., Stewart, S. I., Roper, D., \& Radeloff, V. C. (2016). Places where wildfire potential and social vulnerability coincide in the coterminous United States. International journal of wildland fire, 25(8), 896-908.

Zeileis, A., Kleiber, C., \& Jackman, S. (2008). Regression models for count data in R. Journal of statistical software, 27(8), 1-25. 
Table 1. Indicator sets for the three subindices (CLI, HLI, and NHLI)

Table 1. Indicator Set

\begin{tabular}{|c|c|c|}
\hline Subindex & \multicolumn{2}{|c|}{ Variables } \\
\hline $\begin{array}{l}\text { Hazard Level Index } \\
\text { (HLI) } \\
\text { Table } 1.1\end{array}$ & $\begin{array}{l}\text { Historic Tornado Tracks (1851-2013) } \\
\text { Tropical Storm Tracks (1851-2005) } \\
\text { Tropical Depression Tracks (1851-2005) }\end{array}$ & $\begin{array}{l}\text { Category 1-3 Hurricane Tracks (1851-2005) } \\
\text { Category 4-5 Hurricane Tracks (1851-2005) } \\
\text { Storm Surge (2017 SLOSH MOM Model) }\end{array}$ \\
\hline $\begin{array}{l}\text { Community Level } \\
\text { Index (CLI) } \\
\text { Table } 1.2\end{array}$ & $\begin{array}{l}\text { Median age } \\
\text { Median gross rent } \\
\text { Median dollar value of owner-occupied } \\
\text { housing } \\
\text { Per capita income } \\
\text { Average people per household } \\
\text { \% of each nationality } \\
\text { \% Hispanic } \\
\text { \% unemployed } \\
\text { \% population over } 25 \text { with under } 12 \text { year } \\
\text { education } \\
\text { \% population in poverty } \\
\% \text { renter occupied housing units } \\
\% \text { unoccupied housing units }\end{array}$ & $\begin{array}{l}\text { \% households receiving Social Security benefits } \\
\% \text { ESL population } \\
\% \text { employed in extractive industries } \\
\% \text { children living in married couple families } \\
\% \text { female } \\
\% \text { female headed households } \\
\% \text { population living in mobile homes } \\
\% \text { housing units with no car } \\
\% \text { families earning } \$ 200,000+\text { per year } \\
\% \text { employed in service industries } \\
\% \text { population living in nursing homes }\end{array}$ \\
\hline $\begin{array}{c}\text { Nursing Home Level } \\
\text { Index (NHLI) } \\
\text { Table } 1.3\end{array}$ & $\begin{array}{l}\text { \% of long-stay residents whose need for } \\
\text { help with daily activities has increased } \\
\% \text { of long-stay residents who self-report } \\
\text { moderate to severe pain } \\
\% \text { of high risk long-stay residents with } \\
\text { pressure ulcers } \\
\% \text { of long-stay residents who lose too much } \\
\text { weight } \\
\text { \% of low risk long-stay residents who lose } \\
\text { control of their bowels or bladder } \\
\text { \% of long-stay residents with a catheter } \\
\text { inserted and left in their bladder } \\
\% \text { of long-stay residents with a urinary tract } \\
\text { infection } \\
\text { \% of long-stay residents who have } \\
\text { depressive symptoms } \\
\% \text { of long-stay resident who were physically } \\
\text { restrained }\end{array}$ & $\begin{array}{l}\% \text { of long-stay residents experiencing one or more } \\
\text { falls with major injury } \\
\% \text { of long-stay residents assessed and } \\
\text { appropriately given the seasonal influenza vaccine } \\
\% \text { of long-stay residents assessed and } \\
\text { appropriately given the pneumococcal vaccine } \\
\% \text { of long-stay residents who received an } \\
\text { antipsychotic medication } \\
\% \text { of long-stay residents whose ability to move } \\
\text { independently worsened } \\
\text { \% of long-stay residents who received anti } \\
\text { anxiety or hypnotic medication } \\
\text { Staffing hours per resident per day (CAN, LPN, } \\
\text { RN, Total staffing) } \\
\text { Organization type (For-profit, governmental, non- } \\
\text { profit) }\end{array}$ \\
\hline
\end{tabular}


Table 2. North Carolina mortality groups collected from ICD10 codes on North Carolina death certificates.

\begin{tabular}{|l|l|l|l|}
\hline \multicolumn{5}{|c|}{ Table 2. North Carolina Mortality Groups } \\
\hline \multicolumn{1}{|c|}{ Category } & \multicolumn{1}{|c|}{ ICD10 Codes } & \multicolumn{1}{c|}{ Reference Article(s) } & Sample Size \\
\hline $\begin{array}{l}\text { Deaths Caused by } \\
\text { Stress (2.1) * }\end{array}$ & $\begin{array}{l}\text { F43.0, F43.1, F43.2, F62.0, F94.1, } \\
\text { F94.2 }\end{array}$ & $\begin{array}{l}\text { Dosa et al. 2010, Maercker et al. } \\
2013\end{array}$ & $\mathrm{n}=13$ \\
\hline $\begin{array}{l}\text { External Causes of } \\
\text { Death (2.2) }\end{array}$ & V01 - Y89 & CDC 2002, Thacker et al. 2008 & $\mathrm{n}=76,296$ \\
\hline $\begin{array}{l}\text { Socioeconomic } \\
\text { Deaths (2.3) }\end{array}$ & $\begin{array}{l}\text { B20-24, C00-97, E10-14, G00-98, } \\
\text { I00-I09, I11, I13, I20-51, I60-69, J10- } \\
\text { 18, J40-47, K70, K73-74, V01-Y09, } \\
\text { Y85-86, Y87.0, Y87.1 }\end{array}$ & $\begin{array}{l}\text { Galea, Aherna, \& Karpatic 2005, } \\
\text { Dosa et al. 2010 }\end{array}$ & $\mathrm{n}=806,882$ \\
\hline $\begin{array}{l}\text { Nursing Homes } \\
\text { (2.4) }\end{array}$ & $\begin{array}{l}\text { All codes from the three categories } \\
\text { above }\end{array}$ & $\begin{array}{l}\text { Brown, Rothman, \& Norris 2007, } \\
\text { Brunkard, Namulanda, \& Ratard, } \\
\text { 2008, Cutter \& Finch, 2008, Dosa } \\
\text { et al. 2010, Malik et al. 2018 }\end{array}$ & $\mathrm{n}=147,205$ \\
\hline
\end{tabular}

*Prior research demonstrates that older adults experience negative stressful reactions brought forth by natural disasters, however the sample size for deaths caused by stress for the time period is too small to be used in subsequent analysis. 
Table 3. Comparison of index precision for counties versus census tracts as well as a comparison of the Monte Carlo Simulation versus the manual construction method for each subindex.

\begin{tabular}{|c|c|c|c|c|c|c|c|}
\hline \multicolumn{8}{|c|}{$\begin{array}{l}\text { Table 3. Comparison of Index Precision for Counties versus Census Tract and Monte Carlo } \\
\text { Simulation versus Manual Computation for each subindex }\end{array}$} \\
\hline & & \multicolumn{2}{|c|}{$\begin{array}{l}\text { High Precision } \\
\qquad(\mathrm{CV}<|12|)\end{array}$} & \multicolumn{2}{|c|}{$\begin{array}{l}\text { Moderate Precision } \\
\quad(\mathrm{CV}<|\mathbf{4 0}|)\end{array}$} & \multicolumn{2}{|c|}{$\begin{array}{l}\text { Low Precision } \\
\quad(\mathrm{CV}>|\mathbf{4 0}|)\end{array}$} \\
\hline & & \# of CUs & \% of CUs & \# of CUs & $\%$ of CUs & \# of CUs & \% of CUs \\
\hline & & $\begin{array}{l}\text { (Manual / } \\
\text { Monte Carlo) }\end{array}$ & $\begin{array}{c}\text { (Manual / } \\
\text { Monte Carlo) }\end{array}$ & $\begin{array}{c}\text { (Manual / } \\
\text { Monte Carlo) }\end{array}$ & $\begin{array}{l}\text { (Manual / } \\
\text { Monte Carlo) }\end{array}$ & $\begin{array}{c}\text { (Manual / } \\
\text { Monte Carlo) }\end{array}$ & $\begin{array}{c}\text { (Manual / Monte } \\
\text { Carlo) }\end{array}$ \\
\hline \multirow{2}{*}{ CLI } & County & $0 / 0$ & $0 \% / 0 \%$ & $20 / 20$ & $\begin{array}{l}2.16 \% / \\
2.16 \%\end{array}$ & 904 / 904 & $\begin{array}{l}97.84 \% \text { / } \\
97.84 \%\end{array}$ \\
\hline & Tract & $0 / 0$ & $0 \% / 0 \%$ & 378 / 378 & $\begin{array}{c}2.39 \% / \\
2.39 \%\end{array}$ & $\begin{array}{c}15,364 / \\
15,364\end{array}$ & $\begin{array}{c}97.61 \% / \\
97.61 \%\end{array}$ \\
\hline \multirow{2}{*}{ HLI } & County & $1 / 1$ & $0.1 \% / 0.1 \%$ & 25 / 25 & $\begin{array}{c}2.71 \% / \\
2.71 \%\end{array}$ & 899 / 899 & $\begin{array}{c}97.28 \% \text { / } \\
97.28 \%\end{array}$ \\
\hline & Tract & 13 / 13 & $0.1 \% / 0.1 \%$ & 559 / 574 & $\begin{array}{c}3.55 \% / \\
3.65 \%\end{array}$ & $\begin{array}{c}15,125 / \\
15,168\end{array}$ & $\begin{array}{c}96.45 \% / \\
96.34 \%\end{array}$ \\
\hline \multirow{2}{*}{ NHLI } & County & $0 / 0$ & $0 \%$ / 0\% & 65 / 66 & $\begin{array}{c}7.03 \% / \\
7.14 \% \\
\end{array}$ & 859 / 858 & $\begin{array}{c}92.97 \% \text { / } \\
92.86 \%\end{array}$ \\
\hline & Tract & $0 / 0$ & $0 \% / 0 \%$ & 1412 / 1370 & $\begin{array}{c}8.97 \% / \\
8.70 \%\end{array}$ & $\begin{array}{c}14,330 \text { / } \\
14,372\end{array}$ & $\begin{array}{c}91.03 \% \text { / } \\
91.30 \%\end{array}$ \\
\hline \multirow{2}{*}{ MNHVI } & County & $0 / 0$ & $0 \% / 0 \%$ & 27 / 26 & $\begin{array}{c}2.92 \% / \\
2.81 \%\end{array}$ & 897 / 898 & $\begin{array}{c}97.08 \% \text { / } \\
97.19 \%\end{array}$ \\
\hline & Tract & $0 / 0$ & $0 \% / 0 \%$ & $591 / 549$ & $\begin{array}{c}3.75 \% / \\
3.49 \%\end{array}$ & $\begin{array}{c}15,151 / \\
15,193\end{array}$ & $\begin{array}{c}96.25 \% / \\
96.51 \%\end{array}$ \\
\hline
\end{tabular}


Table 4. The results of the comparison of All Harm from NOAA Storm Events compared to each subindex vulnerability class.

\begin{tabular}{|c|c|c|c|c|c|c|c|c|}
\hline \multicolumn{7}{|c|}{ Table 4. All Harm (Deaths and Injuries) } \\
\hline $\begin{array}{c}\text { Vulnerability } \\
\text { Class }\end{array}$ & $\begin{array}{c}\text { CLI } \\
\text { Harm }\end{array}$ & $\begin{array}{c}\text { CLI } \\
\text { Harm \% }\end{array}$ & $\begin{array}{c}\text { HLI } \\
\text { Harm }\end{array}$ & $\begin{array}{c}\text { HLI } \\
\text { Harm \% }\end{array}$ & $\begin{array}{c}\text { NHLI } \\
\text { Harm }\end{array}$ & $\begin{array}{c}\text { NHLI } \\
\text { Harm \% }\end{array}$ & $\begin{array}{c}\text { MNHVI } \\
\text { Harm }\end{array}$ & $\begin{array}{c}\text { MNHVI } \\
\text { Harm \% }\end{array}$ \\
\hline Very Low & 2070 & $19.64 \%$ & 591 & $5.61 \%$ & 2077 & $19.71 \%$ & 1609 & $15.27 \%$ \\
\hline Low & 1846 & $17.52 \%$ & 931 & $8.83 \%$ & 4008 & $38.03 \%$ & 2062 & $19.57 \%$ \\
\hline Average & 3161 & $\mathbf{3 0 . 0 0 \%}$ & 1990 & $18.88 \%$ & 1625 & $15.42 \%$ & 1544 & $14.65 \%$ \\
\hline High & 1754 & $16.64 \%$ & 2133 & $20.24 \%$ & 1946 & $18.46 \%$ & 3147 & $\mathbf{2 9 . 8 6 \%}$ \\
\hline Very High & 1708 & $16.21 \%$ & 4894 & $\mathbf{4 6 . 4 4 \%}$ & 883 & $8.38 \%$ & 2177 & $20.66 \%$ \\
\hline Above Average & 3462 & $32.85 \%$ & 7027 & $66.48 \%$ & 2829 & $26.84 \%$ & 5324 & $50.52 \%$ \\
\hline
\end{tabular}


Table 5. Coefficients for HURDLE model of Total Harm for each subindex

\begin{tabular}{|c|c|c|}
\hline \multirow{2}{*}{$\begin{array}{c}\text { Table } 5 \\
\text { Predictors }\end{array}$} & \multicolumn{2}{|c|}{ Coefficients for HURDLE model of Total Harm } \\
\hline & Incidence Rate Ratios & Cl \\
\hline \multicolumn{3}{|c|}{ Count Model Coefficients } \\
\hline (Intercept) & 0.48 & $0.00-173.86$ \\
\hline CLI & $0.80 * \star \star$ & $0.75-0.85$ \\
\hline HLI & $2.02 * \star \star$ & $1.50-2.73$ \\
\hline NHLI & 0.54 & $0.29-1.03$ \\
\hline Log(theta) & 0.01 & $0.00-5.09$ \\
\hline \multicolumn{3}{|c|}{ Zero-Hurdle Model Coefficients } \\
\hline (Intercept) & 2.46 *** & $1.97-3.07$ \\
\hline CLI & 0.91 *** & $0.86-0.97$ \\
\hline HLI & 2.38 *** & $1.79-3.16$ \\
\hline NHLI & $0.60 * \star \star$ & $0.37-0.96$ \\
\hline
\end{tabular}


Table 6. The results from a Wilcoxon signed rank test with continuity correction for the 30/90-day pre- and post-storm analysis for Socioeconomic causes of death during Hurricane Irene.

\begin{tabular}{|c|c|c|c|c|c|c|c|}
\hline & & & $\begin{array}{c}\text { \# of } \\
\text { Tracts }\end{array}$ & \begin{tabular}{|c} 
Difference in \\
Deaths 90 \\
Days Pre- \\
Storm vs. Post- \\
Storm (Mean)
\end{tabular} & \begin{tabular}{|c} 
Difference in \\
Deaths 90 \\
Days Pre- \\
Storm vs. Post- \\
Storm (Sum)
\end{tabular} & \begin{tabular}{|c} 
Difference in \\
Deaths 30 \\
Days Pre- \\
Storm vs. Post- \\
Storm (Mean)
\end{tabular} & \begin{tabular}{|} 
Difference in \\
Deaths 30 \\
Days Pre- \\
Storm vs. Post- \\
Storm (Sum)
\end{tabular} \\
\hline \multirow{20}{*}{$\begin{array}{l}\text { Socioeconomic } \\
\text { Causes of Death }\end{array}$} & \multirow{5}{*}{ CLI } & $\begin{array}{l}\text { Very } \\
\text { Low }\end{array}$ & 519 & $-2.03 * * *$ & $-1051 * * *$ & 0.05 & 27 \\
\hline & & Low & 473 & $-2.43 * * *$ & $-1149 * * *$ & -0.06 & -31 \\
\hline & & Average & 442 & $-2.06 * * *$ & $-909 * * *$ & 0.07 & 33 \\
\hline & & High & 411 & $-2.69 * * *$ & $-1104 * * *$ & -0.11 & -46 \\
\hline & & $\begin{array}{l}\text { Very } \\
\text { High } \\
\end{array}$ & 338 & $-2.52 * * *$ & $-853 * * *$ & 0.15 & 50 \\
\hline & \multirow{5}{*}{ HLI } & $\begin{array}{l}\text { Very } \\
\text { Low }\end{array}$ & 569 & $-2.02 * * *$ & $-1150 * * *$ & 0.11 & 65 \\
\hline & & Low & 478 & $-2 * * *$ & $-956 * * *$ & -0.67 & -32 \\
\hline & & Average & 492 & $-2.39 * * *$ & $-1178 * * *$ & 0.12 & 60 \\
\hline & & High & 343 & $-2.59 * * *$ & $-891 * * *$ & 0.05 & 18 \\
\hline & & $\begin{array}{l}\text { Very } \\
\text { High } \\
\end{array}$ & 301 & $-2.96 * * *$ & $-891 * * *$ & $-0.26 *$ & $-78 *$ \\
\hline & \multirow{5}{*}{ NHLI } & $\begin{array}{l}\text { Very } \\
\text { Low }\end{array}$ & 212 & $-3.45 * * *$ & $-732 * * *$ & 0.24 & 51 \\
\hline & & Low & 1845 & $-2.06 * * *$ & $-3804 * * *$ & -0.001 & -2 \\
\hline & & Average & 50 & $-3.66 * * *$ & $-183 * * *$ & 0.04 & 2 \\
\hline & & High & 42 & $-3.17 * * *$ & $-133 * * *$ & -0.38 & -16 \\
\hline & & $\begin{array}{l}\text { Very } \\
\text { High } \\
\end{array}$ & 34 & $-6.29 * * *$ & $-214 * * *$ & -0.06 & -2 \\
\hline & \multirow{5}{*}{ MNHVI } & $\begin{array}{l}\text { Very } \\
\text { Low }\end{array}$ & 543 & $-1.9 * * *$ & $-1030 * * *$ & 0.09 & 48 \\
\hline & & Low & 488 & $-2.46 * * *$ & $-1200 * * *$ & 0 & 0 \\
\hline & & Average & 443 & $-1.81 * * *$ & $-800 * * *$ & 0.05 & 23 \\
\hline & & High & 391 & $-3.12 * * *$ & $-1220 * * *$ & -0.06 & -23 \\
\hline & & $\begin{array}{l}\text { Very } \\
\text { High }\end{array}$ & 318 & $-2.57 * * *$ & $-816 * * *$ & -0.05 & -15 \\
\hline
\end{tabular}


Table 7. The results from a Wilcoxon signed rank test with continuity correction for the 30/90-day pre- and post-storm analysis for external causes of death and deaths in nursing homes during Hurricane Irene.

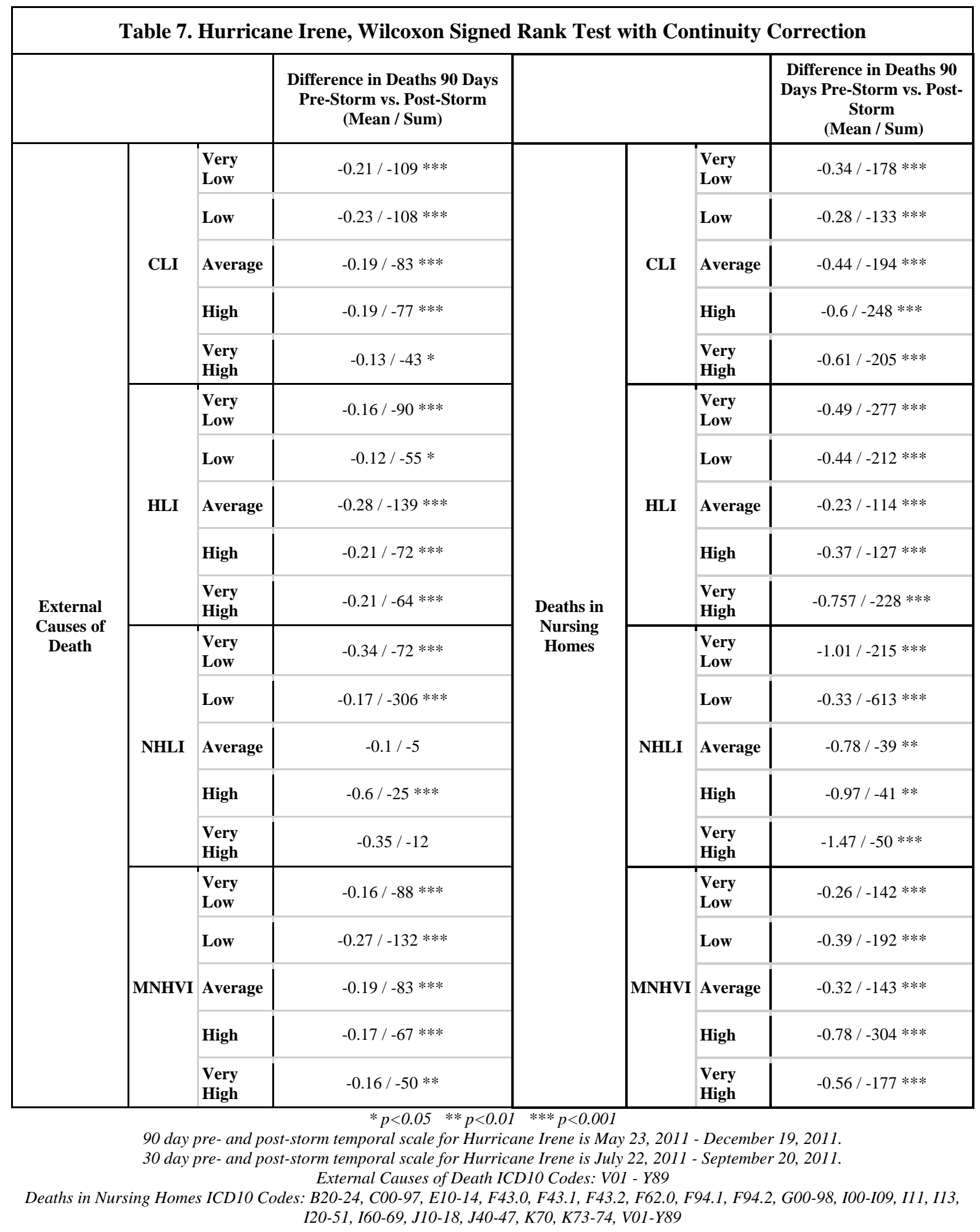


Supplementary Table 1. The results of the comparison of Deaths from NOAA Storm Events compared to each subindex vulnerability class.

\begin{tabular}{|c|c|c|c|c|c|c|c|c|}
\hline \multicolumn{9}{|c|}{ Supplementary Table 1. Deaths from Storms -- NOAA Storm Events Database } \\
\hline \multicolumn{9}{|c|}{ Supplementary Table 1.1 Direct Deaths } \\
\hline Category & $\begin{array}{c}\text { CLI } \\
\text { Deaths }\end{array}$ & $\begin{array}{c}\text { CLI } \\
\text { Death \% }\end{array}$ & $\begin{array}{c}\text { HLI } \\
\text { Deaths }\end{array}$ & $\begin{array}{c}\text { HLI } \\
\text { Death \% }\end{array}$ & $\begin{array}{l}\text { NHLI } \\
\text { Deaths }\end{array}$ & $\begin{array}{c}\text { NHLI } \\
\text { Death \% }\end{array}$ & $\begin{array}{l}\text { MNHVI } \\
\text { Deaths }\end{array}$ & $\begin{array}{l}\text { MNHVI } \\
\text { Death \% }\end{array}$ \\
\hline Very Low & 247 & $17.73 \%$ & 86 & $6.17 \%$ & 370 & $26.56 \%$ & 194 & $13.93 \%$ \\
\hline Low & 275 & $19.74 \%$ & 166 & $11.92 \%$ & 444 & $31.87 \%$ & 336 & $24.12 \%$ \\
\hline Average & 280 & $20.10 \%$ & 196 & $14.07 \%$ & 251 & $18.02 \%$ & 177 & $12.71 \%$ \\
\hline High & 226 & $16.22 \%$ & 318 & $22.83 \%$ & 195 & $14.00 \%$ & 213 & $15.29 \%$ \\
\hline Very High & 365 & $26.20 \%$ & 627 & $45.01 \%$ & 133 & $9.55 \%$ & 473 & $33.96 \%$ \\
\hline \multicolumn{9}{|c|}{ Supplementary Table 1.2 Indirect Deaths } \\
\hline Category & $\begin{array}{c}\text { CLI } \\
\text { Deaths }\end{array}$ & $\begin{array}{c}\text { CLI } \\
\text { Death \% }\end{array}$ & $\begin{array}{c}\text { HLI } \\
\text { Deaths }\end{array}$ & $\begin{array}{c}\text { HLI } \\
\text { Death \% }\end{array}$ & $\begin{array}{l}\text { NHLI } \\
\text { Deaths }\end{array}$ & $\begin{array}{c}\text { NHLI } \\
\text { Death \% }\end{array}$ & $\begin{array}{c}\text { MNHVI } \\
\text { Deaths }\end{array}$ & $\begin{array}{l}\text { MNHVI } \\
\text { Death \% }\end{array}$ \\
\hline Very Low & 25 & $20.66 \%$ & 13 & $10.74 \%$ & 19 & $15.70 \%$ & 18 & $14.88 \%$ \\
\hline Low & 13 & $10.74 \%$ & 10 & $8.26 \%$ & 40 & $33.06 \%$ & 17 & $14.05 \%$ \\
\hline Average & 26 & $21.49 \%$ & 18 & $14.88 \%$ & 25 & $20.66 \%$ & 15 & $12.40 \%$ \\
\hline High & 30 & $24.79 \%$ & 28 & $23.14 \%$ & 30 & $24.79 \%$ & 33 & $27.27 \%$ \\
\hline Very High & 27 & $22.31 \%$ & 52 & $42.98 \%$ & 7 & $5.79 \%$ & 38 & $31.40 \%$ \\
\hline \multicolumn{9}{|c|}{ Supplementary Table 1.3 All Deaths } \\
\hline Category & $\begin{array}{c}\text { CLI } \\
\text { Deaths }\end{array}$ & $\begin{array}{c}\text { CLI } \\
\text { Death \% }\end{array}$ & $\begin{array}{c}\text { HLI } \\
\text { Deaths }\end{array}$ & $\begin{array}{c}\text { HLI } \\
\text { Death \% }\end{array}$ & $\begin{array}{l}\text { NHLI } \\
\text { Deaths }\end{array}$ & $\begin{array}{c}\text { NHLI } \\
\text { Death \% }\end{array}$ & $\begin{array}{l}\text { MNHVI } \\
\text { Deaths }\end{array}$ & $\begin{array}{l}\text { MNHVI } \\
\text { Death \% }\end{array}$ \\
\hline Very Low & 272 & $17.97 \%$ & 99 & $6.54 \%$ & 389 & $25.69 \%$ & 212 & $14.00 \%$ \\
\hline Low & 288 & $19.02 \%$ & 176 & $11.62 \%$ & 484 & $31.97 \%$ & 353 & $23.32 \%$ \\
\hline Average & 306 & $20.21 \%$ & 214 & $14.13 \%$ & 276 & $18.23 \%$ & 192 & $12.68 \%$ \\
\hline High & 256 & $16.91 \%$ & 346 & $22.85 \%$ & 225 & $14.86 \%$ & 246 & $16.25 \%$ \\
\hline Very High & 392 & $25.89 \%$ & 679 & $44.85 \%$ & 140 & $9.25 \%$ & 511 & $33.75 \%$ \\
\hline
\end{tabular}


Supplementary Table 2. The results of the comparison of Injuries from NOAA Storm Events compared to each subindex vulnerability class

\begin{tabular}{|c|c|c|c|c|c|c|c|c|}
\hline \multicolumn{9}{|c|}{ Supplementary Table 2. Injuries from Storms -- NOAA Storm Events Database } \\
\hline \multicolumn{9}{|c|}{ Supplementary Table 2.1 Direct Injuries } \\
\hline Category & $\begin{array}{c}\text { CLI } \\
\text { Injuries }\end{array}$ & $\begin{array}{c}\text { CLI } \\
\text { Injuries \% }\end{array}$ & $\underset{\text { Injuries }}{\text { HLI }}$ & $\begin{array}{c}\text { HLI } \\
\text { Injuries \% }\end{array}$ & $\begin{array}{c}\text { NHLI } \\
\text { Injuries }\end{array}$ & $\begin{array}{c}\text { NHLI } \\
\text { Injuries \% }\end{array}$ & $\begin{array}{l}\text { MNHVI } \\
\text { Injuries }\end{array}$ & $\begin{array}{c}\text { MNHVI } \\
\text { Injuries \% }\end{array}$ \\
\hline Very Low & 1736 & $20.21 \%$ & 483 & $5.62 \%$ & 1530 & $17.81 \%$ & 1348 & $15.69 \%$ \\
\hline Low & 1525 & $17.75 \%$ & 723 & $8.42 \%$ & 3429 & $39.91 \%$ & 1665 & $19.38 \%$ \\
\hline Average & 2810 & $32.71 \%$ & 1716 & $19.97 \%$ & 1305 & $15.19 \%$ & 1319 & $15.35 \%$ \\
\hline High & 1349 & $15.7 \%$ & 1715 & $19.96 \%$ & 1598 & $18.6 \%$ & 2835 & $33.00 \%$ \\
\hline Very High & 1171 & $13.63 \%$ & 3954 & $46.02 \%$ & 729 & $8.49 \%$ & 1424 & $16.58 \%$ \\
\hline \multicolumn{9}{|c|}{ Supplementary Table 2.2 Indirect Injuries } \\
\hline Category & $\begin{array}{c}\text { CLI } \\
\text { Injuries }\end{array}$ & $\begin{array}{c}\text { CLI } \\
\text { Injuries \% }\end{array}$ & $\underset{\text { Injuries }}{\text { HLI }}$ & $\begin{array}{c}\text { HLI } \\
\text { Injuries \% }\end{array}$ & $\begin{array}{c}\text { NHLI } \\
\text { Injuries }\end{array}$ & $\begin{array}{c}\text { NHLI } \\
\text { Injuries \% }\end{array}$ & $\begin{array}{l}\text { MNHVI } \\
\text { Injuries }\end{array}$ & $\begin{array}{c}\text { MNHVI } \\
\text { Injuries \% }\end{array}$ \\
\hline Very Low & 62 & $14.29 \%$ & 9 & $2.07 \%$ & 158 & $36.41 \%$ & 49 & $11.29 \%$ \\
\hline Low & 33 & $7.60 \%$ & 32 & $7.37 \%$ & 95 & $21.89 \%$ & 44 & $10.14 \%$ \\
\hline Average & 45 & $10.37 \%$ & 60 & $13.82 \%$ & 44 & $10.14 \%$ & 33 & $7.60 \%$ \\
\hline High & 149 & $34.33 \%$ & 72 & $16.59 \%$ & 123 & $28.34 \%$ & 66 & $15.21 \%$ \\
\hline Very High & 145 & $33.41 \%$ & 261 & $60.14 \%$ & 14 & $3.23 \%$ & 242 & $55.76 \%$ \\
\hline \multicolumn{9}{|c|}{ Supplementary Table 2.3 All Injuries } \\
\hline Category & $\underset{\text { Injuries }}{\text { CLI }}$ & $\begin{array}{c}\text { CLI } \\
\text { Injuries \% }\end{array}$ & $\begin{array}{c}\text { HLI } \\
\text { Injuries }\end{array}$ & $\begin{array}{c}\text { HLI } \\
\text { Injuries \% }\end{array}$ & $\begin{array}{c}\text { NHLI } \\
\text { Injuries }\end{array}$ & $\begin{array}{c}\text { NHLI } \\
\text { Injuries \% }\end{array}$ & $\begin{array}{l}\text { MNHVI } \\
\text { Injuries }\end{array}$ & $\begin{array}{c}\text { MNHVI } \\
\text { Injuries \% }\end{array}$ \\
\hline Very Low & 1798 & $19.92 \%$ & 492 & $5.45 \%$ & 1688 & $18.70 \%$ & 1397 & $15.48 \%$ \\
\hline Low & 1558 & $17.26 \%$ & 755 & $8.37 \%$ & 3524 & $39.05 \%$ & 1709 & $18.94 \%$ \\
\hline Average & 2855 & $31.63 \%$ & 1776 & $19.68 \%$ & 1349 & $14.95 \%$ & 1352 & $14.98 \%$ \\
\hline High & 1498 & $16.60 \%$ & 1787 & $19.80 \%$ & 1721 & $19.07 \%$ & 2901 & $32.14 \%$ \\
\hline Very High & 1316 & $14.58 \%$ & 4215 & $46.70 \%$ & 743 & $8.23 \%$ & 1666 & $18.46 \%$ \\
\hline
\end{tabular}


Supplementary Table 3. The results from a Wilcoxon signed rank test with continuity correction for the 30/90-day pre- and post-storm analysis for Socioeconomic causes of death during Hurricane Irene.

\begin{tabular}{|c|c|c|c|c|c|c|c|}
\hline \multicolumn{8}{|c|}{ Supplementary Table 3. Hurricane Irene, Exposed Tracts, Wilcoxon Signed Rank Test with Continuity Correction } \\
\hline & & & \begin{tabular}{c|}
$\#$ of \\
Tracts
\end{tabular} & $\begin{array}{l}\text { Difference in } \\
\text { Deaths } 90 \text { Days } \\
\text { Pre-Storm vs. Post- } \\
\text { Storm (Mean) }\end{array}$ & \begin{tabular}{|c|} 
Difference in \\
Deaths 90 Days \\
Pre-Storm vs. Post- \\
Storm (Sum)
\end{tabular} & $\begin{array}{l}\text { Difference in } \\
\text { Deaths } 30 \text { Days } \\
\text { Pre-Storm vs. Post- } \\
\text { Storm (Mean) }\end{array}$ & $\begin{array}{c}\text { Difference in } \\
\text { Deaths } 30 \text { Days } \\
\text { Pre-Storm vs. Post- } \\
\text { Storm (Sum) }\end{array}$ \\
\hline \multirow{20}{*}{$\begin{array}{l}\text { Socioeconomic } \\
\text { Causes of Death }\end{array}$} & \multirow{5}{*}{ CLI } & $\begin{array}{l}\text { Very } \\
\text { Low }\end{array}$ & 125 & $-1.81 * * *$ & $-226 * * *$ & 0.14 & 17 \\
\hline & & Low & 88 & $-3.06 * * *$ & $-269 * * *$ & -0.25 & -22 \\
\hline & & Average & 97 & $-2.94 * * *$ & $-285 * * *$ & -0.37 & -36 \\
\hline & & High & 90 & $-2.77 * * *$ & $-249 * * *$ & -0.23 & -21 \\
\hline & & $\begin{array}{l}\text { Very } \\
\text { High }\end{array}$ & 66 & $-3.27 * * *$ & $-216 * * *$ & -0.08 & -5 \\
\hline & \multirow{5}{*}{ HLI } & $\begin{array}{l}\text { Very } \\
\text { Low }\end{array}$ & 17 & -1.76 & -30 & 0.64 & 11 \\
\hline & & Low & 18 & $-2.44 * *$ & $-44 * *$ & -0.28 & -5 \\
\hline & & Average & 52 & $-2.21 * * *$ & $-115 * * *$ & 0.08 & 4 \\
\hline & & High & 94 & $-2.29 * * *$ & $-215 * * *$ & -0.02 & -2 \\
\hline & & $\begin{array}{l}\text { Very } \\
\text { High }\end{array}$ & 285 & $-2.95 * * *$ & $-841 * * *$ & $-0.26 * *$ & $-75 * *$ \\
\hline & \multirow{5}{*}{ NHLI } & $\begin{array}{l}\text { Very } \\
\text { Low }\end{array}$ & 39 & $-3.77 * * *$ & $-147 * * *$ & 0.15 & 6 \\
\hline & & Low & 394 & $-2.40 * * *$ & $-947 * * *$ & $-0.21 * *$ & $-82 * *$ \\
\hline & & Average & 12 & $-4.17 * *$ & $-50 * *$ & 0.5 & 6 \\
\hline & & High & 10 & -2.9 & -29 & 0.6 & 6 \\
\hline & & $\begin{array}{l}\text { Very } \\
\text { High }\end{array}$ & 11 & $-6.55 * * *$ & $-72 * * *$ & -0.27 & -3 \\
\hline & \multirow{5}{*}{ MNHVI } & $\begin{array}{l}\text { Very } \\
\text { Low }\end{array}$ & 47 & -0.83 & -39 & $0.68 * * *$ & $32 * * *$ \\
\hline & & Low & 51 & $-2.55 * * *$ & $-130 * * *$ & -0.08 & -4 \\
\hline & & Average & 77 & $-2.12 * * *$ & $-163 * * *$ & -0.32 & -25 \\
\hline & & High & 129 & $-3.29 * * *$ & $-425 * * *$ & -0.26 & -34 \\
\hline & & $\begin{array}{l}\text { Very } \\
\text { High }\end{array}$ & 162 & $-3.01 * * *$ & $-488 * * *$ & -0.22 & -36 \\
\hline
\end{tabular}


Supplementary Table 4. The results from a Wilcoxon signed rank test with continuity correction for the 90-day pre- and post-storm analysis for external causes of death and deaths in nursing homes during Hurricane Irene.

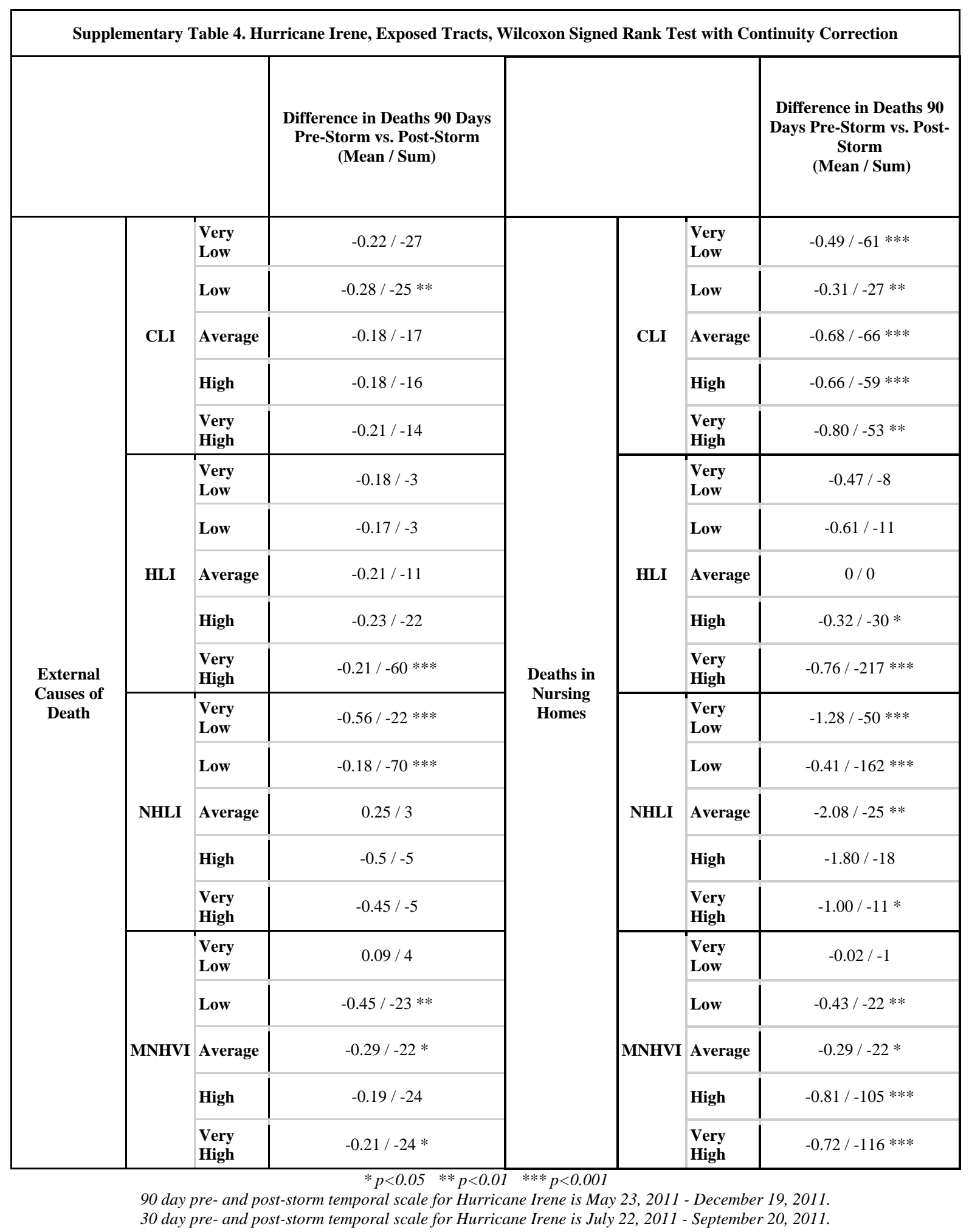




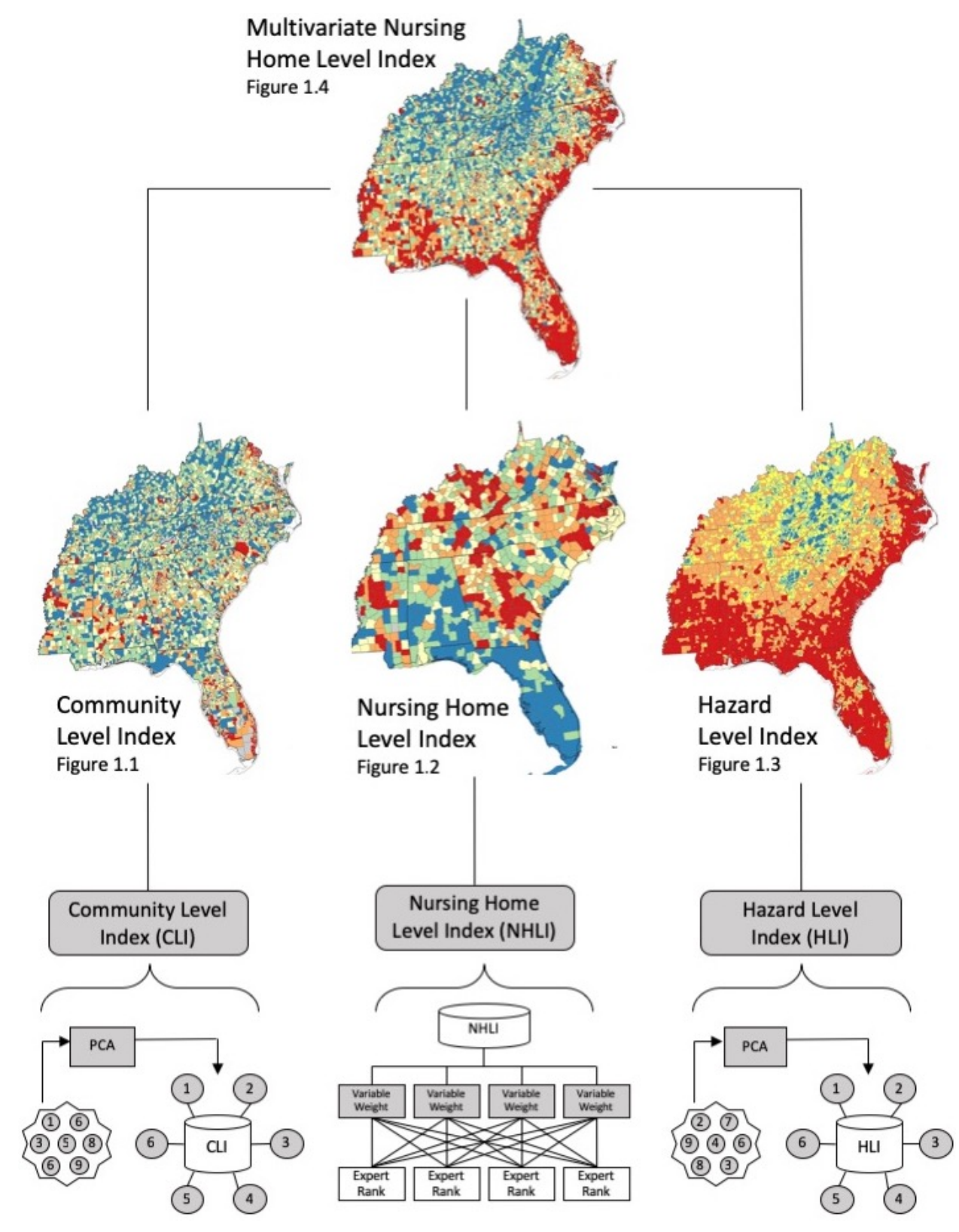

Fig. 1. Inductive Hierarchical Model used to construct the MNHVI. The NHLI is created using the Analytical Hierarchy Process and is represented at the County level (Figure 1.2). The CLI and HLI is created using a Principal Components Analysis and are represented at the Census Tract level (Figures 1.1 and 1.3). The MNHVI is created using the AHP process and is represented at the Census Tract level (Figure 1.4) 


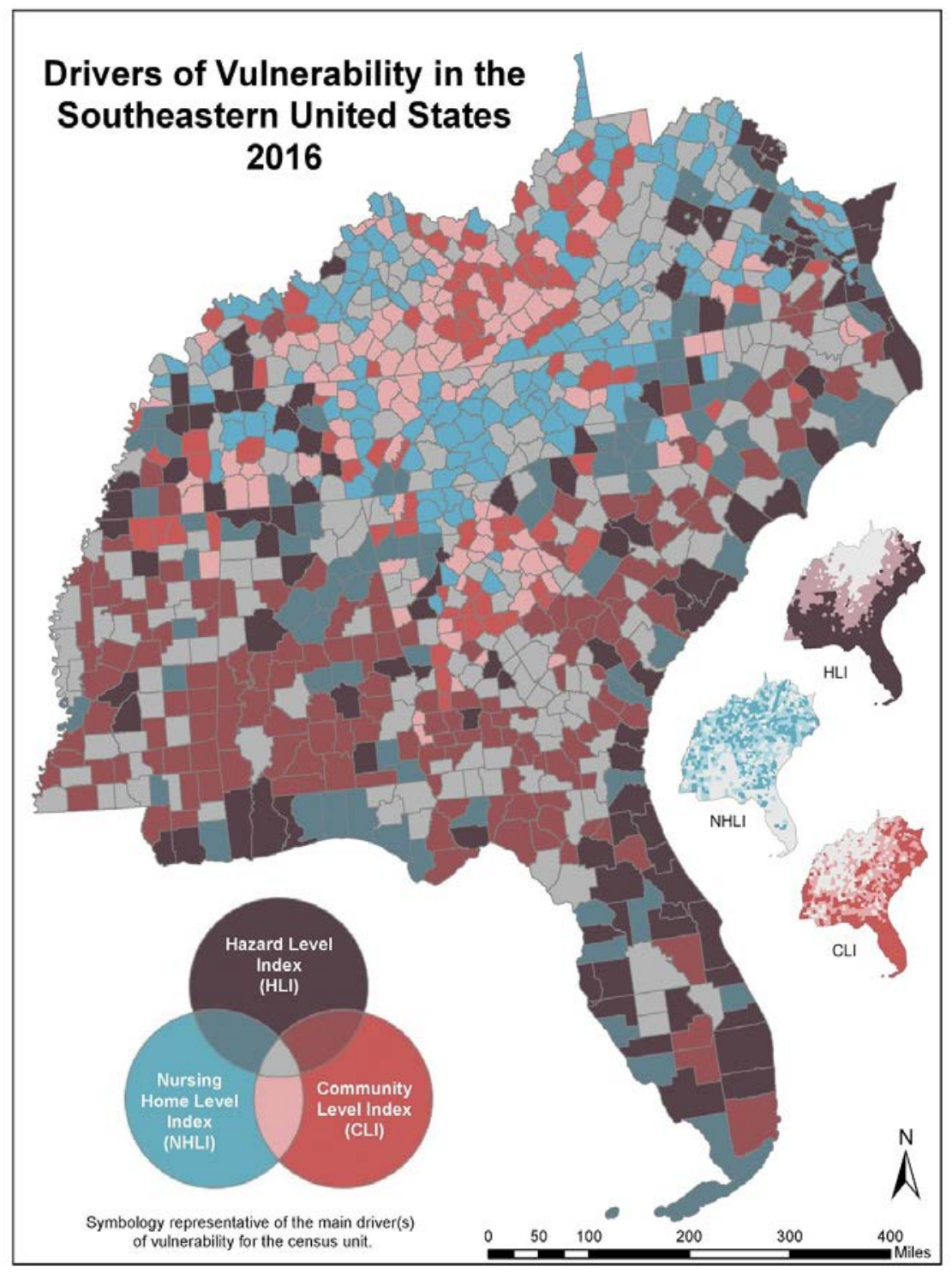

Fig. 2. Trivariate map of vulnerability in the SEUS. Symbology is represented by the main driver of vulnerability for each CU. If there is no definite driver of vulnerability, 'grey' is ascribed to the $\mathrm{CU}$ to denote either equal influence by all three indices. 


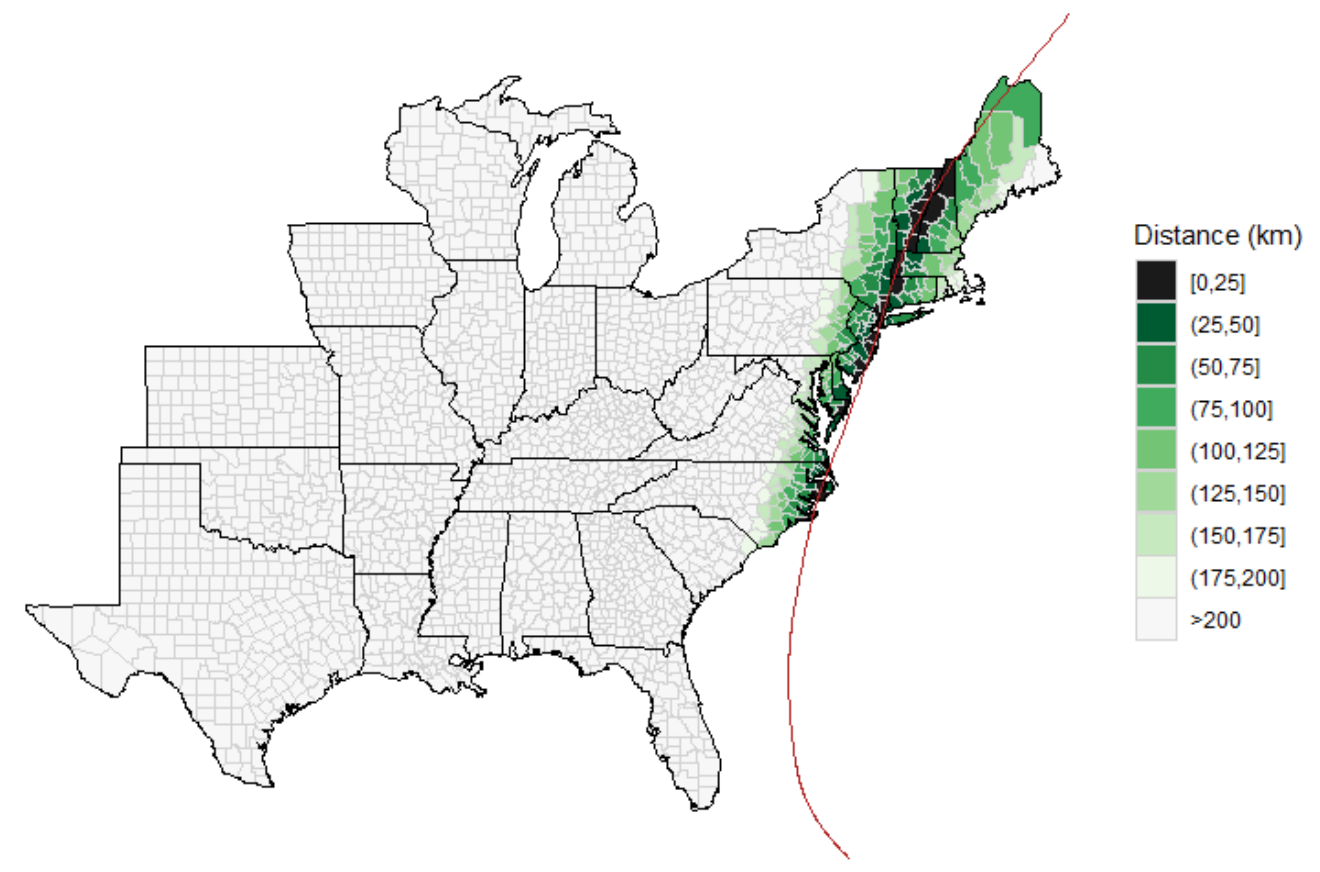

Fig. 3. Census Tracts within exposed counties are subset as tracts directly exposed to Hurricane Irene 

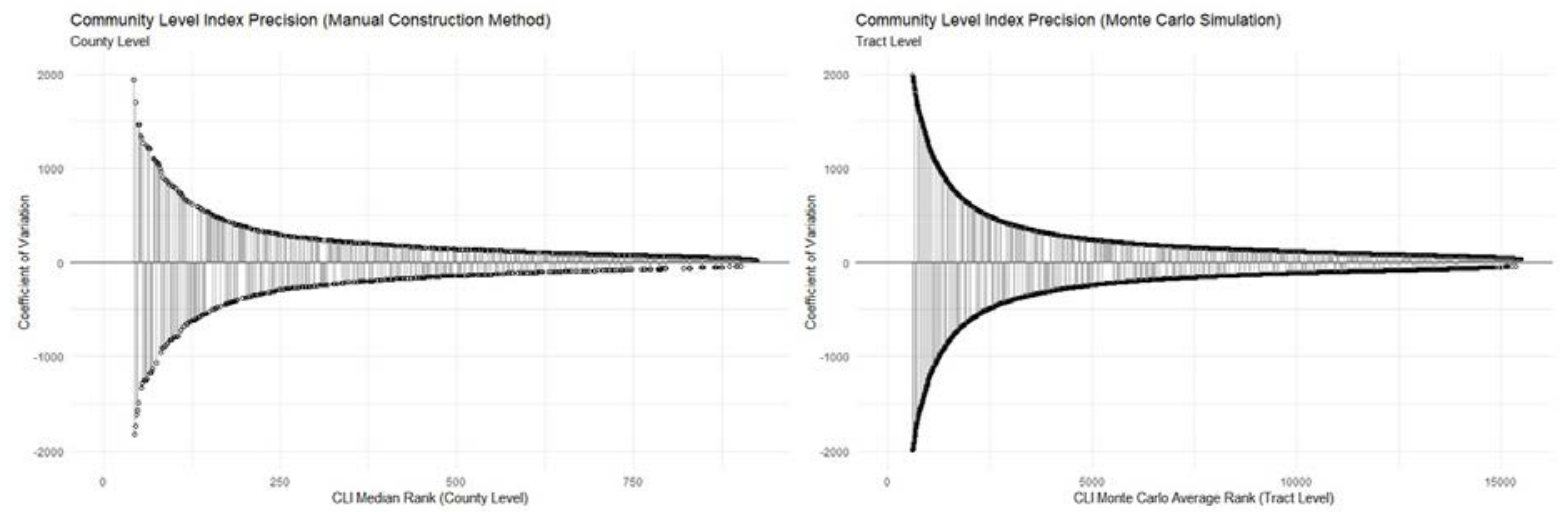

Fig. 4. Community Level Index Precision. Left: County Level using Manual Construction Method. Right: Tract Level using Monte Carlo Simulation. Negative and positive values represent values above and below mean vulnerability (i.e., negative $\mathrm{CV}$ values = below mean vulnerability, positive CV values = above mean vulnerability). 


\section{Vita}

Matthew Jonathan Wilson was born and raised in Kernersville, North Carolina. His parents, Jonathan and Amy Wilson, both attended Appalachian State University. Throughout his childhood, Matthew frequently visited the mountains of North Carolina to visit the place his parents had lived. Upon graduating from Wesleyan Christian Academy in High-Point, North Carolina in May 2015, Matthew pursued an education at King University in Bristol, Tennessee. After one semester, Matthew decided that he would like to follow in his parents' footsteps and transfer to Appalachian State University in Boone, North Carolina.

As an undergraduate, Matthew pursued several academic tracts. Initially, his goal was to earn a degree in Pre-Law with a minor in Public Administration. However, through his general education coursework and a brief introduction in a Public Administration course, Matthew was exposed to the opportunities within the field of Geographic Information Systems (GIS). At that point, Matthew took an internship with the Winston-Salem/Forsyth County School System where he was able to gain hands-on experience working with geographic data and soon changed his major to Geography with a concentration in Geographic Information Systems. Matthew completed his undergraduate degree in three years and immediately entered into a full-time master’s program at Appalachian State University as a member of the Accelerated Admissions Program under the leadership of Dr. Maggie Sugg.

As a graduate student Matthew soon became involved in research examining social vulnerability to natural hazards as well as statistical methods. Throughout his graduate 
career, Matthew was able to expand on his research and present his work at the 2018 and 2019 Annual Meeting of the American Association of Geographers, the 2018 Annual Meeting of the Southeastern Division of the American Association of Geographers, the 2018 Carolinas Climate Resilience Conference, the 2018 and 2019 Celebration of Student Research and Creative Activities Symposium, and the 2019 North Carolina Geographic Information Systems Conference. Matthew was listed as the first author on an article titled Identifying Multivariate Vulnerability of Nursing Home Facilities throughout the Southeastern United States which was published in the International Journal of Disaster Risk Reduction in March 2019. Matthew was acknowledged and awarded with the 2018-2019 Zigli Graduate Student Research Award, the 2018 Julian Yoder Scholarship in Geography, the 2018 Stephen Vacendak Graduate Fellowship for Geography, and the 2018-2019 G. Herbert Stout Award.

Upon graduating with a Master of Arts in Geography in May 2019, Matthew plans to publish his thesis in a peer-reviewed academic journal and pursue a career in GIS with the consideration of pursuing a Ph.D. in Geography in the future. 